\title{
On the Drivers and Predictability of Seasonal-to-Interannual Variations in Regional Sea Levelo
}

\author{
C. D. Roberts, D. Calvert, N. Dunstone, L. Hermanson, M. D. Palmer, and D. Smith \\ Met Office Hadley Centre, Exeter, United Kingdom
}

(Manuscript received 3 December 2015, in final form 20 July 2016)

\begin{abstract}
Observations and eddy-permitting ocean model simulations are used to evaluate the drivers of sea level variability associated with 15 modes of climate variability covering the Atlantic, Pacific, Indian, and Southern Oceans. Sea level signals are decomposed into barotropic, steric, and inverted barometer contributions. Forcings are decomposed into surface winds, buoyancy fluxes, and Ekman pumping. Seasonal-to-interannual sea level variability in the low latitudes is governed almost entirely by the thermosteric response to wind forcing associated with tropical modes of climate variability. In the extratropics, changes to dynamic sea level associated with atmospheric modes of variability include a substantial barotropic response to wind forcing, particularly over the continental shelf seas. However, wind-driven steric changes are also important in some locations. On interannual time scales, wind-forced steric changes dominate, although heat and freshwater fluxes are important in the northwest Atlantic, where low-frequency sea level variations are associated with changes in the Atlantic meridional overturning circulation. Using the version 3 of the Met Office Decadal Prediction System (DePreSys3), the predictability of large-scale dynamic sea level anomalies on seasonal-to-interannual time scales is evaluated. For the first year of the hindcast simulations, DePreSys3 exhibits skill exceeding persistence over large regions of the Pacific, Atlantic, and Indian Oceans. Skill is particularly high in the tropical Indo-Pacific because of the accurate initialization and propagation of thermocline depth anomalies associated with baroclinic adjustments to remote wind forcing. Skill in the extratropics is hindered by the limited predictability of wind anomalies associated with modes of atmospheric variability that dominate local and/or barotropic responses.
\end{abstract}

\section{Introduction}

\section{a. Background and motivation}

The timing and magnitude of coastal sea level extremes are largely governed by the phase of astronomical tides and the sea level response to meteorological phenomena (e.g., storm surges, ocean swell, surface waves, and wave setup; Wong et al. 2014). However, changes to local time-mean sea level due to long-term trends and natural modes of climate variability exert a significant influence on the background risk of such extremes (Nicholls et al. 1999). The physical consequences of extreme sea level events include coastal submergence

Supplemental information related to this paper is available at the Journals Online website: http://dx.doi.org/10.1175/JCLI-D-15-0886.s1.

Corresponding author address: C. D. Roberts, Met Office Hadley Centre, Fitzroy Road, Exeter EX1 3P, United Kingdom.

E-mail: chris.roberts@metoffice.gov.uk and flooding, saltwater intrusion into ground and surface waters, and coastal erosion, all of which can have negative social and economic impacts (Wong et al. 2014; Nicholls and Cazenave 2010).

Over the period 1993-2009, global mean sea level (GMSL) increased at a rate of $3.2 \pm 0.4 \mathrm{~mm} \mathrm{yr}^{-1}$ because of thermal expansion and the transfer of mass from the continents to the oceans (Church and White 2011). However, on monthly-to-decadal time scales, regional sea level anomalies associated with large-scale modes of internal climate variability can dominate long-term changes. For example, sea level anomalies in the tropical Pacific associated with the year-to-year changes in the El NiñoSouthern Oscillation (ENSO) can exceed $30 \mathrm{~cm}$ (Becker et al. 2012), which is larger than the 21-cm increase in GMSL that occurred between 1880 and 2009 (Church and White 2011). There are also substantial geographic variations in rates of sea level rise on decadal time scales due to the influence of climate variability (Zhang and Church 2012). For example, rates of sea level rise in the western tropical Pacific during the last decade have been 2-3 times 
higher than the global mean (Stammer et al. 2013). Skillful and timely prediction of such anomalies will allow coastal communities to better assess the risk of extreme coastal flooding events and therefore inform strategies to mitigate the associated impacts.

\section{b. Dynamic sea level}

In this study, we focus on the seasonal-to-interannual variations in dynamic sea level (DSL) associated with leading modes of climate variability. We define DSL as regional deviations from GMSL associated with local variations in ocean mass and density arising from changes in the barotropic and baroclinic ocean circulation, respectively. Following Gill and Niller (1973), DSL anomalies can be expressed as

$$
\mathrm{DSL}=\eta_{\text {barotropic }}+\eta_{\text {steric }}=\frac{p_{b}}{g \rho_{0}}-\frac{1}{\rho_{0}} \int_{-H}^{0} \Delta \rho(T, S, p) d z,
$$

where $g$ is acceleration due to gravity, $T$ is ocean potential temperature, $S$ is salinity, $p$ is pressure, $p_{b}$ is pressure at the ocean bottom, $\rho_{0}$ is a reference density, and $\Delta \rho$ is potential density relative to a reference value. By focusing on the dynamic component of regional sea level, we neglect contributions from global thermosteric sea level rise, vertical land motion, changes to Earth's geoid, and loss or addition of mass to the ocean. In addition, our definition of DSL does not include contributions from the inverted barometer (IB) effect (i.e., the change in sea level induced by changes in local atmospheric pressure). Observational estimates of DSL are derived from satellite altimeter data and are adjusted to remove IB effects. However, where specified, we separately evaluate contributions from the IB effect to compare with changes in DSL.

\section{c. Drivers of seasonal-to-interannual sea level variability}

To understand the origins and limits of DSL predictability, it is instructive to consider the processes that drive variability. These can include local and remote atmospheric forcings and intrinsic (i.e., unforced) ocean variability arising from nonlinear processes. DSL signals associated with local atmospheric forcings and rapid barotropic adjustments present a particular challenge because they require accurate prediction of the evolving atmospheric state, which has significantly less "memory" than the ocean. In contrast, ocean advective processes and baroclinic responses to remote forcings can be captured through accurate initialization of the ocean dynamics without requiring predictability of the atmospheric forcing. Table 1 summarizes some of the previously described processes responsible for DSL variability along with their typical time scales. These dynamic sources of variability are often linked to large-scale modes of climate variability such as ENSO and the North Atlantic Oscillation (NAO; Stammer et al. 2013), though others have argued that a substantial fraction of interannual-to-decadal time-scale variability can be explained by the baroclinic response to stochastic wind forcing (e.g., Frankignoul et al. 1997).

Local sea level responses to atmospheric forcing include steric changes due to surface buoyancy forcings (e.g., Gill and Niller 1973; Ferry et al. 2000; Cabanes et al. 2006), Ekman pumping in the presence of stratification (Cabanes et al. 2006; Piecuch and Ponte 2011; Cummins and Lagerloef 2004), and along-equator heave of the thermocline balanced by changes to zonal wind stress (Merrifield and Maltrud 2011; Timmermann et al. 2010). Remote sea level responses to atmospheric forcings include changes associated with baroclinic and barotropic wave adjustments to wind forcing (Wyrtki 1975; Forget and Ponte 2015; Cabanes et al. 2006; Qiu 2002; Frankignoul et al. 1997; Hakkinen 2001; Sturges and Hong 1995; Qiu and Chen 2006), advective anomalies in response to buoyancy-forced water mass transformations (e.g., Hakkinen 2001; Köhl 2014), and time-dependent Sverdrup dynamics associated with zonally integrated wind stress curl (Cabanes et al. 2006; Qiu 2002). Unforced intrinsic variability also contributes to changes in sea level and arises because of nonlinear ocean processes such as barotropic and baroclinic instability (e.g., Chelton et al. 2007; Penduff et al. 2011).

Barotropic redistribution of mass is important for DSL variability on intra-annual time scales (Fukumori et al. 1998; Vinogradova et al. 2007). On interannual time scales, barotropic changes play a role in the high latitudes and over shallow shelf seas (Forget and Ponte 2015; Piecuch et al. 2013), but in most other regions DSL variability is largely steric in nature (Cazenave and Llovel 2010; Forget and Ponte 2015; Köhl 2014). In the low and midlatitudes, steric signals are almost entirely thermosteric and driven by the adiabatic displacement of isopycnals driven by wind stress (Köhl 2014; Forget and Ponte 2015; Stammer et al. 2013). In contrast, sea level variability in the North Atlantic western boundary and subpolar gyre has been linked to the diabatic response to basin-scale thermal forcing and changes in the overturning circulation (e.g., Hakkinen 2001). Salinitydriven (i.e., halosteric) changes make an important contribution in the Arctic, but elsewhere in the ocean they are mostly offset by density-compensating thermosteric changes (Antonov et al. 2002; Köhl 2014).

\section{d. Recent studies of sea level predictability}

Several studies have demonstrated the ability of statistical techniques to make useful predictions of sea 
TABLE 1. Processes contributing to seasonal-to-interannual dynamic sea level variability.

\begin{tabular}{|c|c|c|c|}
\hline Process & Driver & Approx time scale & References \\
\hline \multicolumn{4}{|l|}{ Remotely forced } \\
\hline \multirow{10}{*}{$\begin{array}{l}\text { Baroclinic Rossby } \\
\text { waves }\end{array}$} & \multirow[t]{10}{*}{ Wind stress } & \multirow[t]{10}{*}{ Months to decades } & Cabanes et al. (2006) \\
\hline & & & Cummins and Lagerloef (2004) \\
\hline & & & Forget and Ponte (2015) \\
\hline & & & Frankignoul et al. (1997) \\
\hline & & & McGregor et al. (2007) \\
\hline & & & Qiu (2002) \\
\hline & & & Qiu and Chen (2006) \\
\hline & & & Qiu and Chen (2010) \\
\hline & & & Sturges and Hong (1995) \\
\hline & & & Vivier et al. (1999) \\
\hline Boundary-forced & \multirow{3}{*}{$\begin{array}{l}\text { Perturbations at an eastern } \\
\text { boundary }\end{array}$} & \multirow[t]{3}{*}{ Months to decades } & Cabanes et al. (2006) \\
\hline \multirow[t]{2}{*}{ Rossby waves } & & & Jacobs et al. (1994) \\
\hline & & & Qiu and Chen (2006) \\
\hline Kelvin waves & \multirow[t]{4}{*}{ Wind stress } & \multirow[t]{4}{*}{ Months to years } & Enfield and Allen (1980) \\
\hline & & & Forget and Ponte (2015) \\
\hline & & & McGregor et al. (2007) \\
\hline & & & Wyrtki (1975) \\
\hline Time-dependent & \multirow[t]{4}{*}{ Zonal integral of wind stress curl } & \multirow[t]{4}{*}{ Months to years } & Cabanes et al. (2006) \\
\hline Sverdrup balance & & & Qiu (2002) \\
\hline & & & Stammer (1997) \\
\hline & & & Vivier et al. (1999) \\
\hline \multirow[t]{4}{*}{ Steric (advection) } & \multirow{4}{*}{$\begin{array}{l}\text { Advection of temperature/salinity } \\
\text { anomalies }\end{array}$} & \multirow[t]{4}{*}{ Years to decades } & Cabanes et al. (2006) \\
\hline & & & Forget and Ponte (2015) \\
\hline & & & Köhl (2014) \\
\hline & & & Piecuch and Ponte (2011) \\
\hline \multirow{4}{*}{$\begin{array}{l}\text { Buoyancy-forced cir- } \\
\text { culation changes } \\
\text { Barotropic } \\
\text { adjustments }\end{array}$} & \multirow{2}{*}{$\begin{array}{l}\text { Heat and freshwater fluxes in regions } \\
\text { of water mass formation }\end{array}$} & \multirow[t]{2}{*}{ Years to decades } & Hakkinen (2001) \\
\hline & & & Hakkinen and Rhines (2004) \\
\hline & \multirow{2}{*}{$\begin{array}{l}\text { Wind stress and mass fluxes; steric } \\
\text { changes over sloping topography }\end{array}$} & \multirow[t]{2}{*}{ Days to years } & Fukumori et al. (1998) \\
\hline & & & Vinogradova et al. (2007) \\
\hline \multicolumn{4}{|l|}{ Locally forced } \\
\hline \multirow[t]{5}{*}{ Ekman pumping } & \multirow[t]{5}{*}{ Local wind stress curl } & Months to years & Cabanes et al. (2006) \\
\hline & & & Hakkinen (2001) \\
\hline & & & Kelly et al. (1993) \\
\hline & & & Köhl (2014) \\
\hline & & & Vivier et al. (1999) \\
\hline Steric (local) & Local air-sea buoyancy fluxes & Months to decades & Cabanes et al. (2006) \\
\hline & & & Ferry et al. (2000) \\
\hline & & & Gill and Niller (1973) \\
\hline & & & Köhl (2014) \\
\hline & & & Piecuch and Ponte (2011) \\
\hline & & & Stammer (1997) \\
\hline & & & Vivier et al. (1999) \\
\hline Equatorial thermo- & Zonal wind stress & Months to decades & Merrifield and Maltrud (2011) \\
\hline cline heave & & & Timmermann et al. (2010) \\
\hline Unforced (i.e., intrinsic) & & & \\
\hline Eddies & Baroclinic-barotropic instability & Days to years & Cabanes et al. (2006) \\
\hline & & & Chelton et al. (2007) \\
\hline Mixing & Temperature and salinity gradients & Years to decades & Piecuch and Ponte (2011) \\
\hline
\end{tabular}

level variability in the tropical Pacific at lead times of several months (e.g., Xue and Leetmaa 2000; Chowdhury et al. 2007, 2014). These methods rely on historical relationships between sea surface temperature (SST), surface winds, and sea level to make predictions of variability at selected tide gauge locations. Seasonal outlooks based on these statistical methods are currently made available online by the National Oceanic and Atmospheric Administration (NOAA) for the U.S.-affiliated Pacific Islands (http://www.weather. gov/peac/sealevel).

Although statistical predictions are useful, they are reliant on the use of a training dataset such that their application is limited to locations with sufficiently long 
TABLE 2. Indices of climate variability used in this study.

\begin{tabular}{llll}
\hline \multicolumn{1}{c}{ Mode of variability } & Abbreviation & \multicolumn{1}{c}{ Type of index } & \multicolumn{1}{c}{ Reference } \\
\hline Antarctic Oscillation & AAO & Atmospheric pressure & Mo (2000) \\
Atlantic meridional mode & AMM & SST and surface winds & Chiang and Vimont (2004) \\
Atlantic Niño-1 index & ANINO & SST & Lutz et al. (2013) \\
East Atlantic pattern & EA & Atmospheric pressure & Barnston and Livezey (1987) \\
East Atlantic-Western Russia pattern (Eurasia-2) & EAWR & Atmospheric pressure & Barnston and Livezey (1987) \\
East Pacific-North Pacific pattern & EPNP & Atmospheric pressure & Barnston and Livezey (1987) \\
El Niño Modoki index & EMI & SST & Ashok et al. (2007) \\
Indian Ocean dipole & IOD & SST & Saji et al. (1999) \\
North Atlantic Oscillation & NAO & Atmospheric pressure & Barnston and Livezey (1987) \\
North Pacific index & NP & Atmospheric pressure & Trenberth and Hurrell (1994) \\
Pacific Niño-3.4 index & ENSO & SST & Trenberth (1997) \\
Pacific-North American pattern & PNA & Atmospheric pressure & Barnston and Livezey (1987) \\
Polar-Eurasia pattern & POL & Atmospheric pressure & Barnston and Livezey (1987) \\
Scandinavian pattern (Eurasia-1) & SCA & Atmospheric pressure & Barnston and Livezey (1987) \\
West Pacific pattern & WP & Atmospheric pressure & Barnston and Livezey (1987) \\
\hline
\end{tabular}

records of reliable and well-documented tide gauge observations. In contrast, global climate models that include sophisticated numerical representations of the dynamics and thermodynamics of the oceans and atmosphere can, in principle, provide a forecast for any coastal or openocean location. Such models have recently been applied to investigate the predictability of sea level on seasonal (Miles et al. 2014; McIntosh et al. 2015) and decadal (Polkova et al. 2014, 2015) time scales.

Miles et al. (2014) used a dynamical general circulation model (GCM) to predict regional sea level anomalies over the global ocean at lead times of up to 7 months. Although using an ocean model with a relatively coarse horizontal resolution $\left(\sim 2^{\circ}\right)$, Miles et al. (2014) found skill in the prediction of sea level anomalies in the tropical Pacific. In a follow-up study, McIntosh et al. (2015) extended the analysis to coastal locations in the tropical Indian and Pacific Oceans and emphasized the value of dynamical GCMs by demonstrating skill in the prediction of coastal sea level that exceeded existing statistical approaches. Polkova et al. (2015) used a GCM-based decadal prediction system and found predictability of steric sea level in the subtropics for a lead time of 2-5 yr. They attributed this skill to westward-propagating baroclinic Rossby waves. However, this skill was difficult to separate from persistence at high latitudes, where Rossby waves can take decades to cross a basin.

\section{e. This study}

Here, we combine observations and experiments with eddy-permitting GCMs to evaluate the drivers and predictability of DSL on seasonal-to-interannual time scales. In particular, we focus on the response of DSL to 15 leading modes of climate variability covering the
Atlantic, Indian, Pacific, and Southern Oceans. Section 2 describes the data, models, and methods we use in our analysis. Section 3 evaluates the drivers of DSL associated with modes of climate variability on seasonalto-interannual time scales. Section 4 evaluates the predictability of large-scale DSL variability in a state-ofthe-art coupled forecasting system. Our main conclusions are summarized in section 5 .

\section{Data and model configurations}

\section{a. Satellite altimeter data}

We use satellite altimeter data from a multimission reanalysis produced by the European Space Agency (ESA) Climate Change Initiative (CCI; http://www.esasealevel-cci.org). This product is described in detail by Ablain et al. (2015). Additional preprocessing steps applied for this study include bilinear interpolation to a regular $1^{\circ} \times 1^{\circ}$ grid and removal of the global trend by subtraction of the area-weighted global mean from each monthly field. Monthly anomalies are calculated by subtracting the climatological seasonal cycle for the period 1993-2012.

\section{b. Climate mode indices}

Here, we evaluate the drivers of sea level anomalies associated with 15 large-scale modes of climate variability (see Table 2) chosen for their coverage of the major ocean basins and importance for seasonal-tointerannual climate variability, including some that generally receive less attention in the sea level literature. It is well-known that some modes of climate variability, such as ENSO and the NAO, are associated with basin-scale changes in sea level (Wyrtki 1975; Enfield 
and Allen 1980; Chelton and Davis 1982; Zhang and Church 2012; Goddard et al. 2015; Tsimplis et al. 2006; Yan et al. 2004; Woolf et al. 2003; Woodworth et al. 2007). However, less well known modes of climate variability also have a significant influence on regional sea level and the risk of extreme events (Menéndez and Woodworth 2010). For example, Fagherazzi et al. (2005) found that variations in the east Atlantic-western Russia (EAWR) and polar-Eurasian (POL) indices were linked to the frequency of flooding in Venice.

Monthly indices are retrieved from NOAA (http:// www.esrl.noaa.gov/psd/data/climateindices/list/) and the KNMI climate explorer (https://climexp.knmi.nl/). In addition, the El Niño Modoki index (EMI) and Atlantic Niño-1 index are based on data from Ashok et al. (2007) and Lutz et al. (2013), respectively. Each index is detrended and anomalized relative to its mean seasonal cycle for the period 1993-2012 in order to isolate changes on seasonal-to-interannual time scales.

\section{c. Ocean model sensitivity experiments}

To complement our analysis of observational data, we perform sensitivity experiments with an eddy-permitting ocean model. Our experiments are designed to isolate the historical variations in DSL attributable to the following processes: 1) mechanical forcing from surface winds and 2) buoyancy fluxes that arise because of variations in the overlying atmospheric state. We use version 3.4 of the Nucleus for European Models of the Ocean (NEMO) global ocean model (Madec 2008) configured with 75 vertical levels and an eddy-permitting horizontal resolution of $\sim 0.25^{\circ}$ coupled to the Los Alamos National Laboratory sea ice model (CICE), version 4.1 (Hunke and Lipscomb 2010). Surface boundary conditions are specified using a mixture of time-varying and climatological "normal year" versions of the updated Coordinated Ocean-Ice Reference Experiments, version 2 (CORE-II) dataset (Large and Yeager 2009). Turbulent air-sea fluxes are calculated using the bulk formulae of Large and Yeager (2004). The normal year forcing consists of a single annual cycle that is representative of climatological conditions but also includes realistic propagation of synoptic weather patterns such that the ocean is excited by high-frequency forcings (Large and Yeager 2004). Previous studies have demonstrated that eddy-permitting configurations of the NEMO model are useful tools for simulating variability of sea level (Penduff et al. 2010) and large-scale ocean dynamics (Roberts et al. 2013). The specific version of NEMO we use is designated Global Ocean 5 (GO5) and is described in detail by Megann et al. (2014).

The four sensitivity experiments used in this study can be summarized as follows:
1) CTRL includes interannual variability in all atmospheric boundary conditions used to calculate air-sea fluxes of heat, freshwater, and momentum.

2) CTRL_NYF is run parallel to CTRL but with atmospheric boundary conditions constrained to follow a repeating normal year cycle such that interannual variability can only arise as a consequence of adjustments to the initial conditions and unforced intrinsic ocean variability. This experiment is used to correct for multidecadal adjustments in our ocean experiments that are unrelated to interannual variability in the atmosphere (i.e., drift).

3) WIND is as CTRL, but with normal year atmospheric boundary conditions used to calculate all airsea exchanges other than momentum fluxes. Note that this experiment still includes some interannual variations in fluxes of sensible/latent heat and outgoing longwave radiation that arise in response to wind-induced changes in SST. This contribution to heat flux variability is dominant in regions of equatorial upwelling, but because the feedback is negative (i.e., negative SST anomalies induce a heat flux anomaly that warms the ocean), it acts to damp ocean variability and we therefore do not consider it a buoyancy forcing.

4) BUOY includes interannual variability in all atmospheric boundary conditions that affect buoyancy fluxes (i.e., precipitation, downward radiation fluxes, air temperature, humidity, and wind speed) but uses normal year winds to calculate air-sea momentum fluxes. This experiment therefore includes variations in heat and freshwater fluxes that originate from the atmosphere and can be considered to be driving the ocean.

A more complete description of these experiments, including our drift-correction strategy, is included as supplementary material.

\section{d. DePreSys3}

To evaluate the predictability of DSL on seasonal-tointerannual time scales, we use version 3 of the Met Office Decadal Prediction System (DePreSys3; Dunstone et al. 2016). DePreSys3 uses the Hadley Centre Global Environmental Model version 3 at the global coupled model 2.0 (HadGEM3-GC2) configuration (Williams et al. 2015). It has an atmospheric resolution of $0.83^{\circ}$ longitude $\times 0.55^{\circ}$ latitude (about $60 \mathrm{~km}$ at midlatitudes), 85 atmospheric levels, and an upper boundary at $85 \mathrm{~km}$ near the mesopause. The ocean model used is the NEMO GO5 configuration described in section 2c. DePreSys3 uses a data assimilation scheme that nudges toward observed analyses in the atmosphere, ocean, and sea ice 
TABLE 3. Dominant drivers of sea level variability associated with different modes of climate variability. When more than one type of sea level response or atmospheric driver is involved, they are listed in order of importance.

\begin{tabular}{llll}
\hline \hline Mode & \multicolumn{1}{c}{ Region } & \multicolumn{1}{c}{ Sea level responses } & \multicolumn{1}{c}{ Atmospheric forcings } \\
\hline AAO & Southern Ocean & IB, barotropic & Winds \\
AMM & Tropical Atlantic & Thermosteric & Winds, buoyancy fluxes \\
ANINO & Tropical Atlantic & Thermosteric & Winds \\
EA & North Atlantic & IB, thermosteric, barotropic, halosteric & Winds, buoyancy fluxes, Ekman pumping \\
EAWR & Northeast Atlantic & IB, barotropic & Winds \\
EMI & Indo-Pacific & Thermosteric, IB, halosteric & Winds, buoyancy fluxes \\
ENSO & Indo-Pacific & Thermosteric, IB, halosteric & Winds, buoyancy fluxes \\
EPNP & North Pacific & IB, thermosteric, halosteric, barotropic & Winds, buoyancy fluxes, Ekman pumping \\
IOD & Indian Ocean & Thermosteric, halosteric, IB & Winds, buoyancy fluxes \\
NAO & North Atlantic & IB, barotropic, thermosteric, halosteric & Winds, buoyancy fluxes, Ekman pumping \\
NP & North Pacific & IB, barotropic, thermosteric & Winds, Ekman pumping \\
PNA & North Pacific & IB, barotropic, thermosteric & Winds, Ekman pumping \\
POL & North Atlantic & Thermosteric, halosteric, barotropic, IB & Winds, buoyancy \\
SCA & Northeast Atlantic & IB, thermosteric, barotropic & Winds \\
WP & North Pacific & IB, barotropic, thermosteric & Winds, buoyancy \\
\hline
\end{tabular}

(Knight et al. 2014) during an assimilation run of the coupled model. The atmosphere is nudged to 6-hourly fields of ERA-Interim (Dee et al. 2011) temperatures and winds with a 6-hourly relaxation time scale. The ocean is nudged with a 10-day relaxation time scale toward monthly mean fields of 3D temperature and salinity from a statistical ocean analysis based on global covariances (Smith and Murphy 2007; Smith et al. 2015). Sea ice concentration is nudged to monthly mean fields from the HadISST dataset (Rayner et al. 2003) using a 24-h relaxation time scale. In contrast to previous versions, DePreSys 3 assimilates absolute values of temperature and salinity rather than adding observed anomalies onto the model climatology. This approach is sometimes referred to as "full field" initialization. No direct observations of sea level are used to constrain the DePreSys3 analysis.

Hindcasts (retrospective forecasts) cover the period 1960-2014 with a total of 25 start dates spaced 2-3 yr apart between 1960 and 2008 and 1 yr apart from 2008 onward. Each hindcast consists of 10 ensemble members that are started from the initial conditions provided by the assimilation run on 1 November. The ensemble is created by using different seeds to a stochastic physics scheme (MacLachlan et al. 2015). The assimilation run and hindcasts have full knowledge of external forcing datasets (e.g., greenhouse gases, aerosols, ozone, and solar and volcanic forcings) as per the CMIP5 protocol (Taylor et al. 2012) and follow the representative concentration pathway 4.5 (RCP4.5) after 2005 (Meinshausen et al. 2011).

Forecasts from dynamic models using full-field initialization have a tendency to drift toward a "preferred" model climatology, owing to systematic errors in the model simulation. These biases can be accounted for using a lead-time-dependent correction diagnosed from a set of hindcasts (Smith et al. 2013). This correction is necessary if time series from individual hindcasts are being evaluated or if forecast skill is calculated using a measure of deviation (e.g., root-mean-square errors). In contrast, Pearson correlation coefficients calculated using data averaged over a specified forecast period are insensitive to model biases and therefore do not require a lead-time-dependent correction (Smith et al. 2013). For this reason, we evaluate predictive skill for each lead time using correlation coefficients between hindcast ensemble means and equivalent periods in the data assimilating model analysis. The model analysis of DSL is used to assess predictive skill in DePreSys3 because of the limited length of the satellite altimeter record. For this reason, our estimates of skill do not take into account uncertainties in the initial ocean state.

\section{Results}

\section{a. Observed and simulated dynamic sea level variability}

Many previous studies have discussed the dynamical origins and complex geographical distribution of processes responsible for sea level variability (see Table 1). Here, we complement the existing literature by investigating the sea level response associated with 15 leading modes of climate variability using a combination of satellite data and sensitivity experiments with an eddy-permitting ocean model. A summary of the main results from this section is presented in Table 3 .

To begin, we calculate the spatial fingerprints of DSL associated with each mode of variability. Fingerprints are defined as the differences in DSL between positive and negative phases of the associated climate index and 
are calculated using composite means of the 50 most positive and 50 most negative events during the period 1993-2012 (Fig. 1). As expected, there are large changes in DSL associated with tropical modes of climate variability such as ENSO. These signals are particularly evident in the Pacific and Indian Oceans, but less so in the Atlantic. The role for wind-forced baroclinic waves in tropical modes of variability such as ENSO has been understood for several decades (e.g., Wyrtki 1975; Enfield and Allen 1980). Propagating Rossby and Kelvin waves are particularly clear in the tropics and along coastal-equatorial waveguides when composite patterns of DSL are calculated using different lags (see supplementary Fig. 1 in supplementary material).

Extratropical modes of climate variability are also linked to distinct changes in DSL. For example, the NAO is associated with a clear tripole pattern of DSL that exhibits particularly large signals in continental shelf regions such as the Baltic and Mediterranean. However, the DSL signal associated with extratropical modes of variability is typically of a similar (or smaller) magnitude to changes because of the IB effect (Fig. 2). Moreover, in many cases the IB effect and dynamic changes compensate one another [e.g., the central North Pacific during North Pacific index (NP) events]. In other instances, the IB and DSL changes are additive and are therefore more likely to have significant coastal impacts (e.g., the NAO impact on the northeastern United States and the EA impact on the west coast of the United Kingdom and Ireland). This comparison emphasizes that skillful prediction of sea level in the extratropics requires accurate predictions of both the ocean and atmospheric state.

We recalculate the same sea level fingerprints using output from the eddy-permitting ocean model experiment, CTRL (Fig. 1). Each model composite is calculated using the 50 most positive (or negative) months of the associated climate index within the 1993-2009 period of overlap between the altimeter data and our model experiments. In general, the model CTRL simulation does an excellent job of reproducing the DSL signal associated with modes of seasonal-to-interannual climate variability. However, there are some deficiencies worth noting, including the tendency for anomalies in the tropical Pacific associated with ENSO and EMI to extend too far north. Lead-lag analysis of model composite patterns (not shown) reveals this particular bias is a result of Rossby waves emitted from the eastern Pacific boundary at $\sim 10^{\circ} \mathrm{N}$ that propagate westward too rapidly compared to observations, suggesting a stratification bias in this region. Other deficiencies include a tendency for the model to underestimate the response of the North Atlantic marginal seas to NAO variability and inaccurate responses to the EA in parts of the North Sea, Baltic Sea, and Mediterranean Sea. Despite these shortcomings, the overall agreement with the observed signals justifies the use of our model sensitivity experiments to understand the processes driving DSL variability.

\section{b. Isolating the drivers of dynamic sea level variability}

Separation of the local barotropic and steric contributions to changes in DSL in CTRL (Fig. 3) reveals that a substantial fraction of the DSL signal associated with high-latitude modes of climate variability is barotropic in nature, particularly on the continental shelves. Steric signals are also important for extratropical modes of variability in the North Atlantic (EA and NAO) and North Pacific (PNA and EPNP), but less so in the Southern Ocean (AAO). These results are consistent with previous studies that have emphasized the role of barotropic variability in the high latitudes and over shallow shelf seas (Vinogradova et al. 2007). In contrast, changes in DSL associated with tropical modes of variability in the Indian, Pacific, and Atlantic Oceans are almost entirely steric.

To investigate the role of temperature and salinity in sea level variability, we decompose the steric signal into thermosteric and halosteric components as follows

$$
\begin{aligned}
\eta_{\text {thermosteric }} & =-\frac{1}{\rho_{0}} \int_{-H}^{0} \Delta \rho(T, \bar{S}, p) d z \text { and } \\
\eta_{\text {halosteric }} & =-\frac{1}{\rho_{0}} \int_{-H}^{0} \Delta \rho(\bar{T}, S, p) d z,
\end{aligned}
$$

where $\bar{T}$ and $\bar{S}$ are climatological values for temperature and salinity, respectively. This decomposition reveals that steric changes associated with the modes of climate variability in Fig. 3 are almost exclusively due to changes in temperature, with changes in salinity mostly acting to offset a fraction of the thermosteric signal (Fig. 4). An exception is the EPNP pattern in the northeast Pacific, where halosteric effects appear to be important.

To identify the relative role of the winds and buoyancy forcings in driving DSL changes associated with each mode of climate variability, we calculate the same composite patterns using the model simulations WIND and BUOY (Fig. 5). These experiments demonstrate that changes in DSL associated with seasonal-tointerannual modes of climate variability are largely explained by the response to wind forcing. Buoyancy forcings also make a contribution to steric changes associated with some modes, notably in the tropics (e.g., AMM, ENSO, and EMI) and the North Atlantic (NAO, EA, and POL). Our results for the NAO are consistent 


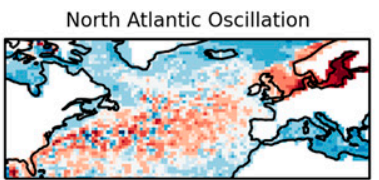

East Atlantic/Western Russia Pattern
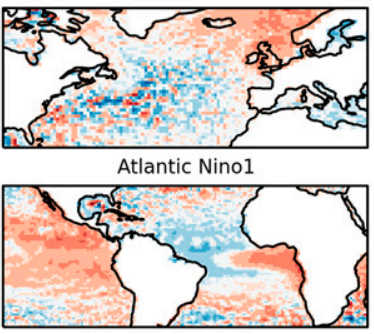

West Pacific Pattern

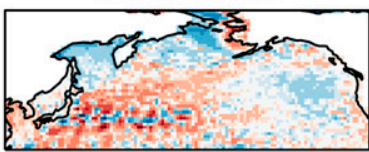

El Nino Modoki Index

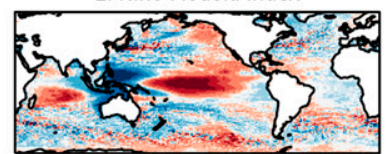

East Atlantic Pattern
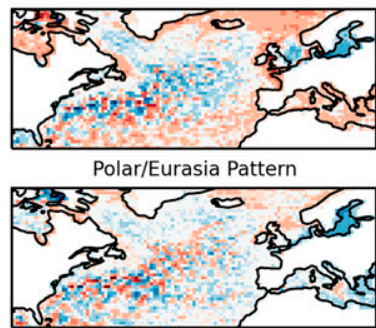

North Pacific Index

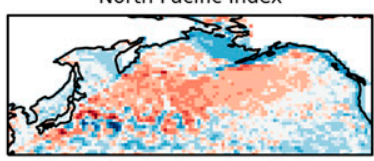

Pacific/North American Pattern

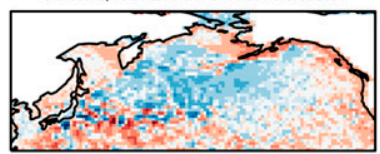

Indian Ocean Dipole Mode

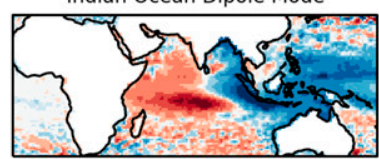

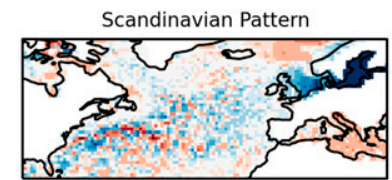

Atlantic Meridional Mode

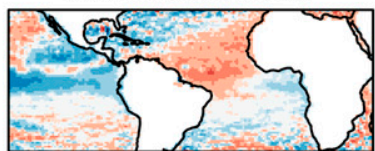

East Pacific/North Pacific Pattern

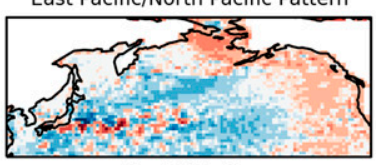

Nino3.4 Index

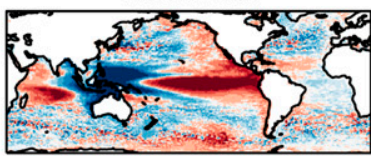

Antarctic Oscillation

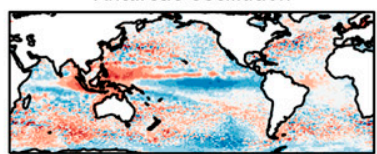

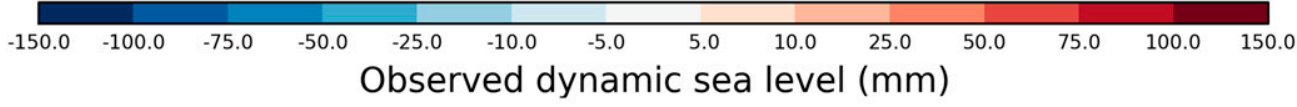

North Atlantic Oscillation

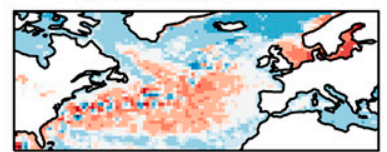

East Atlantic/Western Russia Pattern
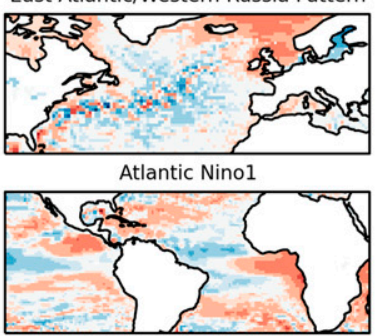

West Pacific Pattern

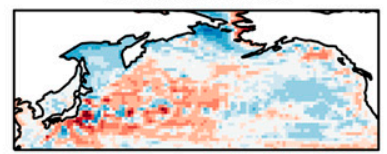

El Nino Modoki Index

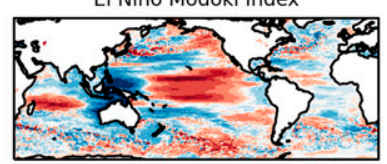

East Atlantic Pattern

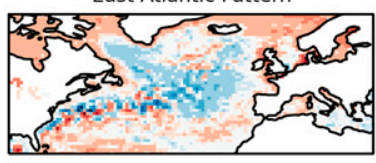

Polar/Eurasia Pattern

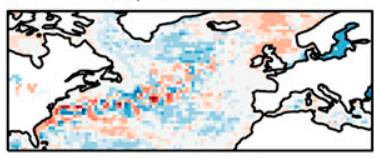

North Pacific Index

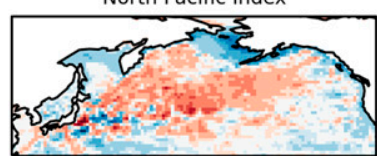

Pacific/North American Pattern

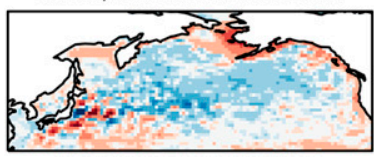

Indian Ocean Dipole Mode

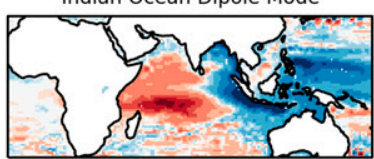

Scandinavian Pattern

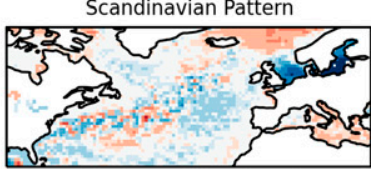

Atlantic Meridional Mode

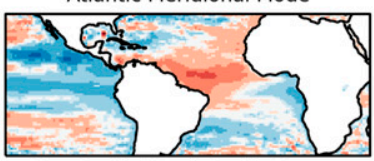

East Pacific/North Pacific Pattern
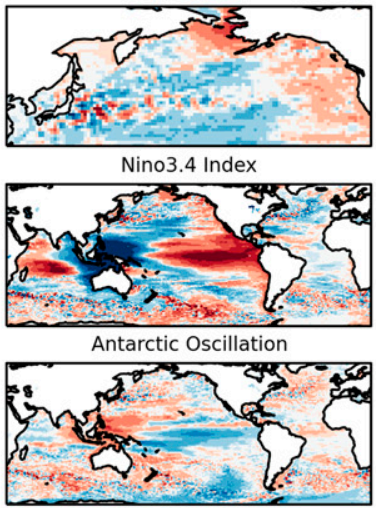

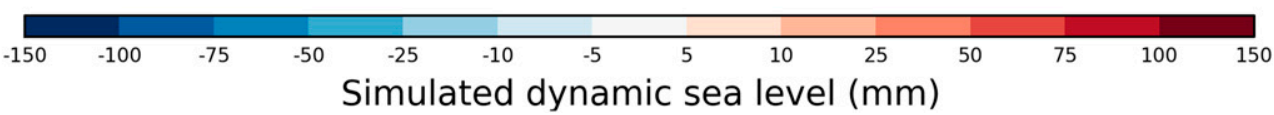

FIG. 1. Dynamic sea level (mm) fingerprints associated with 15 modes of climate variability from (top) altimeter data and (bottom) experiment CTRL. Fingerprints are defined as the difference between composite means of the 50 most positive and 50 most negative months of the associated climate index. 


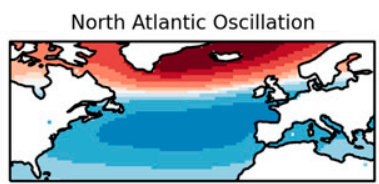

East Atlantic/Western Russia Pattern
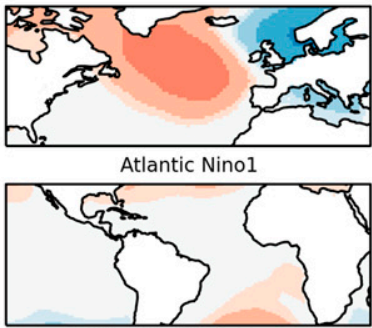

West Pacific Pattern
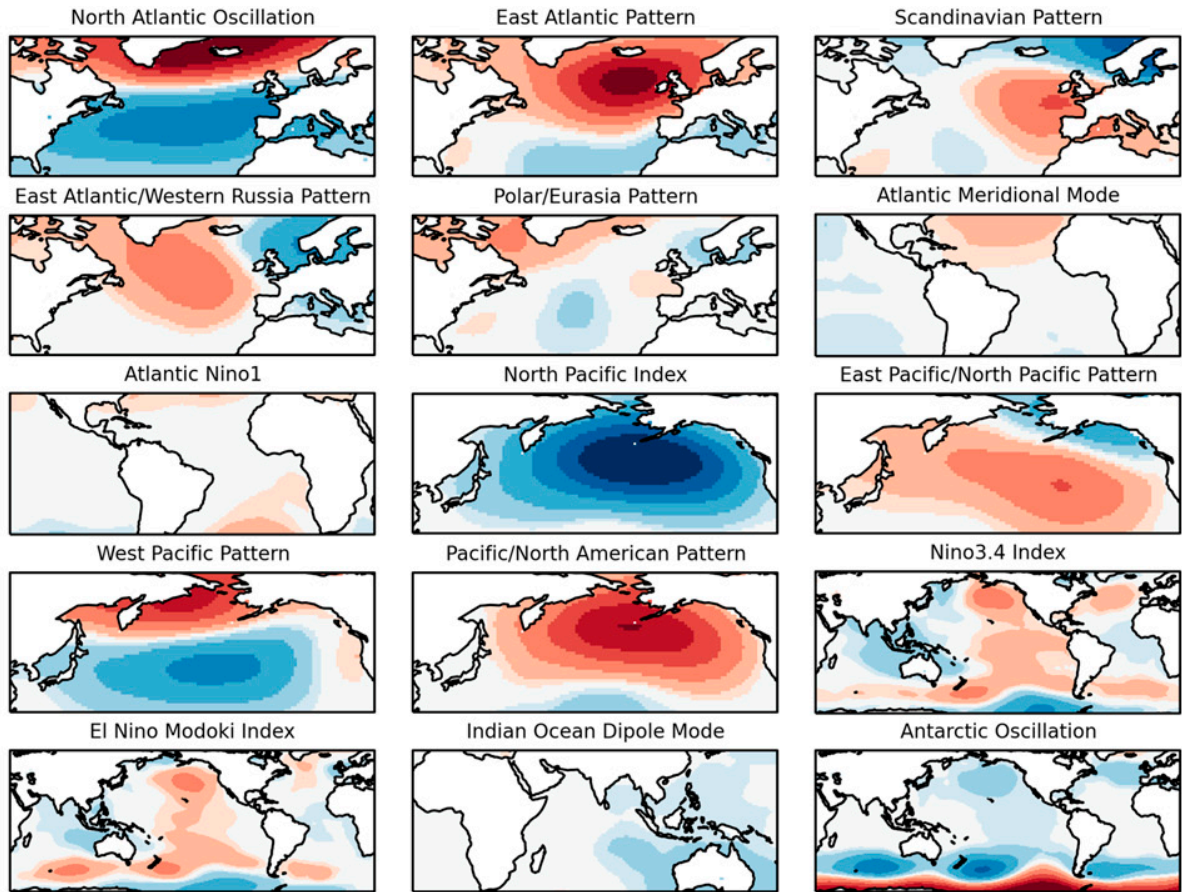

East Pacific/North Pacific Pattern

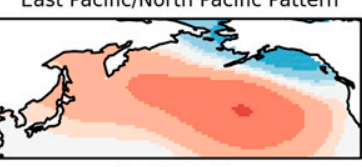

Pacific/North American Pattern
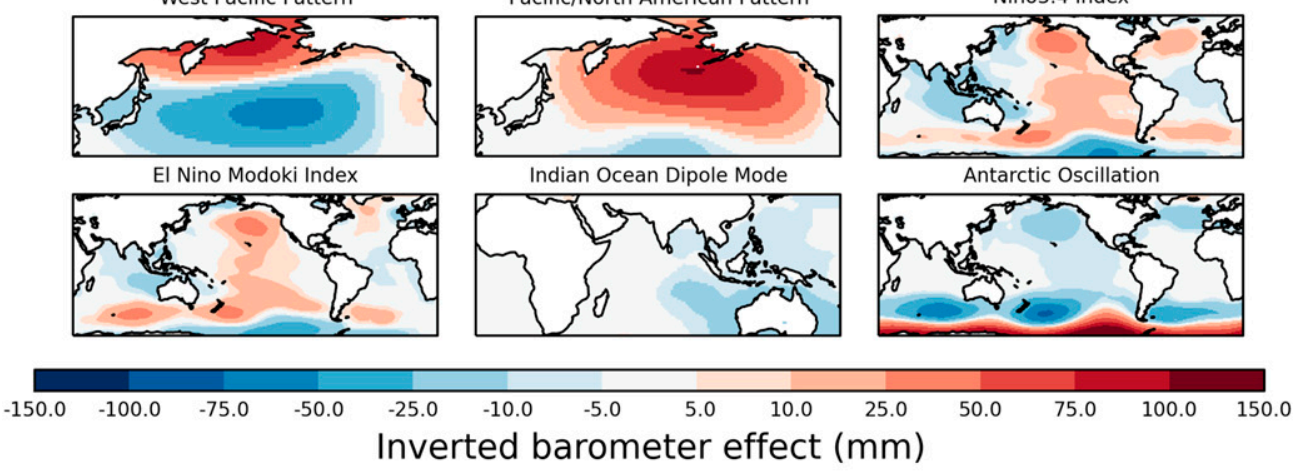

North Atlantic Oscillation

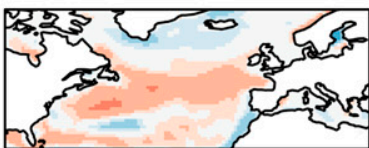

East Atlantic/Western Russia Pattern

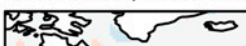

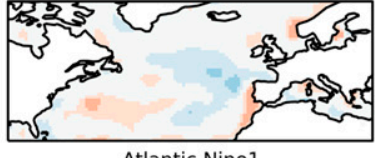

Atlantic Ninol

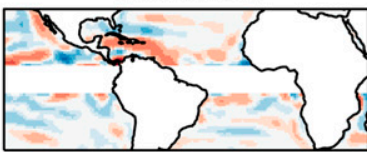

West Pacific Pattern

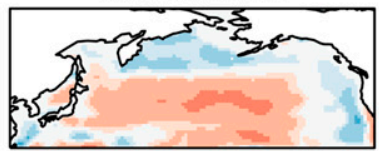

El Nino Modoki Index

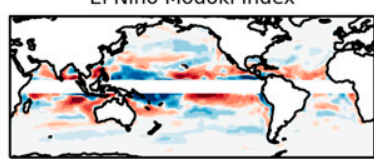

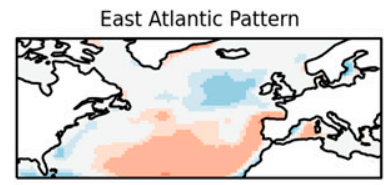

Polar/Eurasia Pattern

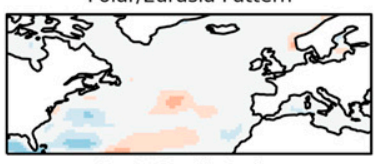

North Pacific Index

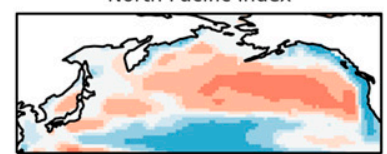

Pacific/North American Pattern

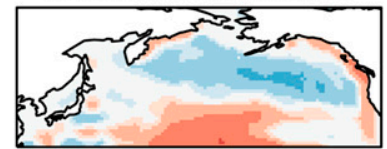

Indian Ocean Dipole Mode

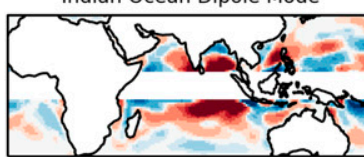

Scandinavian Pattern

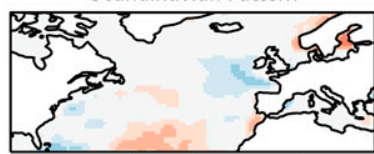

Atlantic Meridional Mode

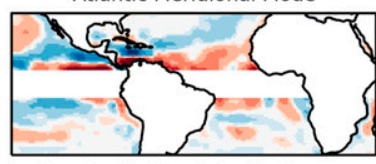

East Pacific/North Pacific Pattern
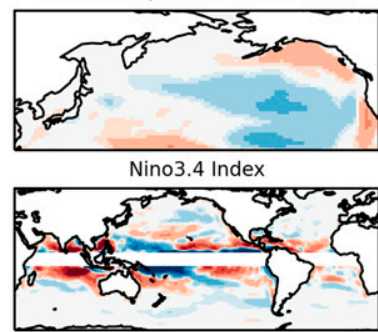

Antarctic Oscillation

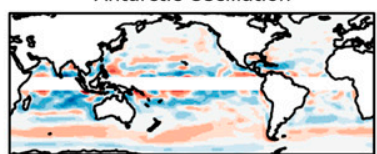

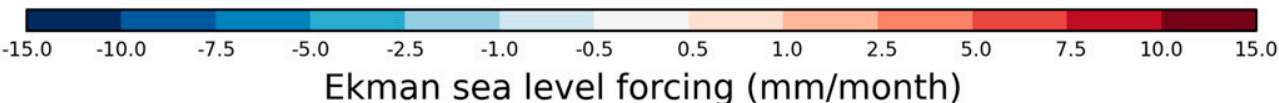

FIG. 2. As in Fig. 1, but for (top) the IB effect (mm) defined as $\eta_{\mathrm{IB}}=-p_{\text {surface }} \rho_{0} / g$ and (bottom) Ekman forcing of sea level $\left(\mathrm{mm} \mathrm{month}{ }^{-1}\right)$. Fingerprints are calculated using surface pressure data and 10-m wind velocities from the NCEP reanalysis (Kalnay et al. 1996). 


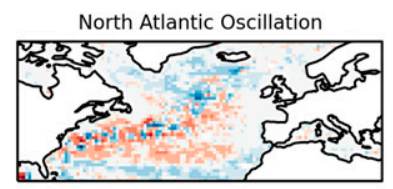

East Atlantic/Western Russia Pattern
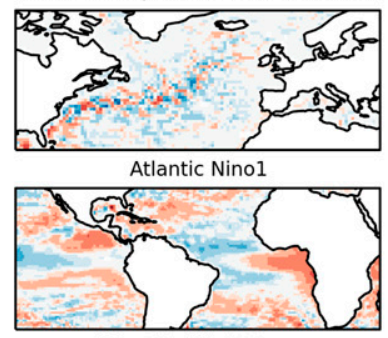

West Pacific Pattern
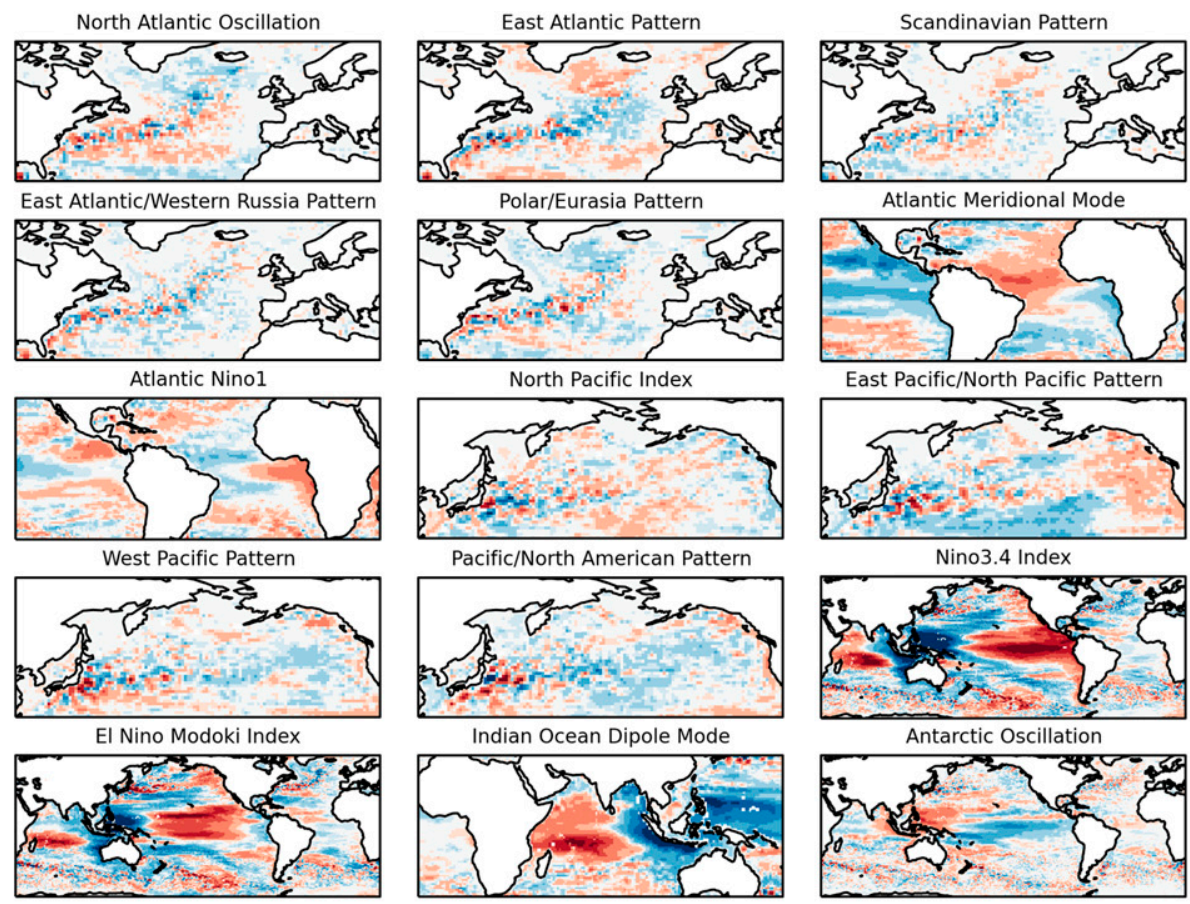

North Pacific Index

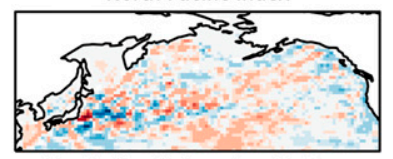

Pacific/North American Pattern
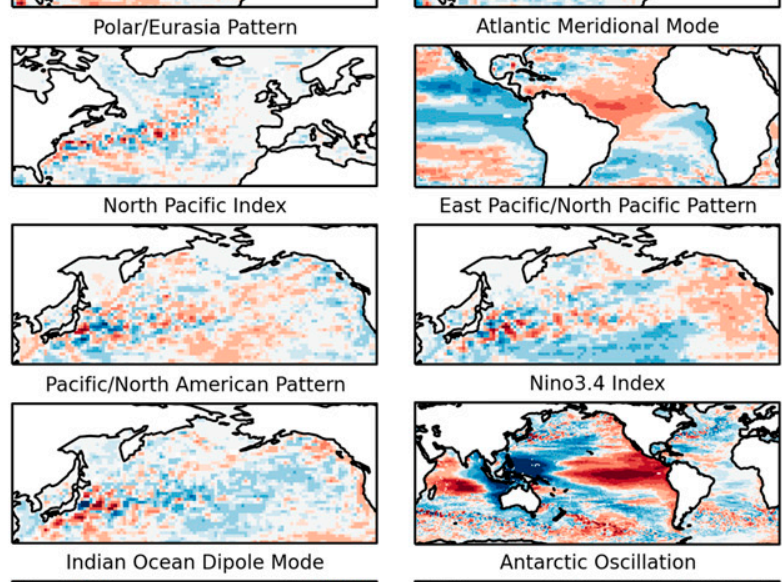

East Pacific/North Pacific Pattern
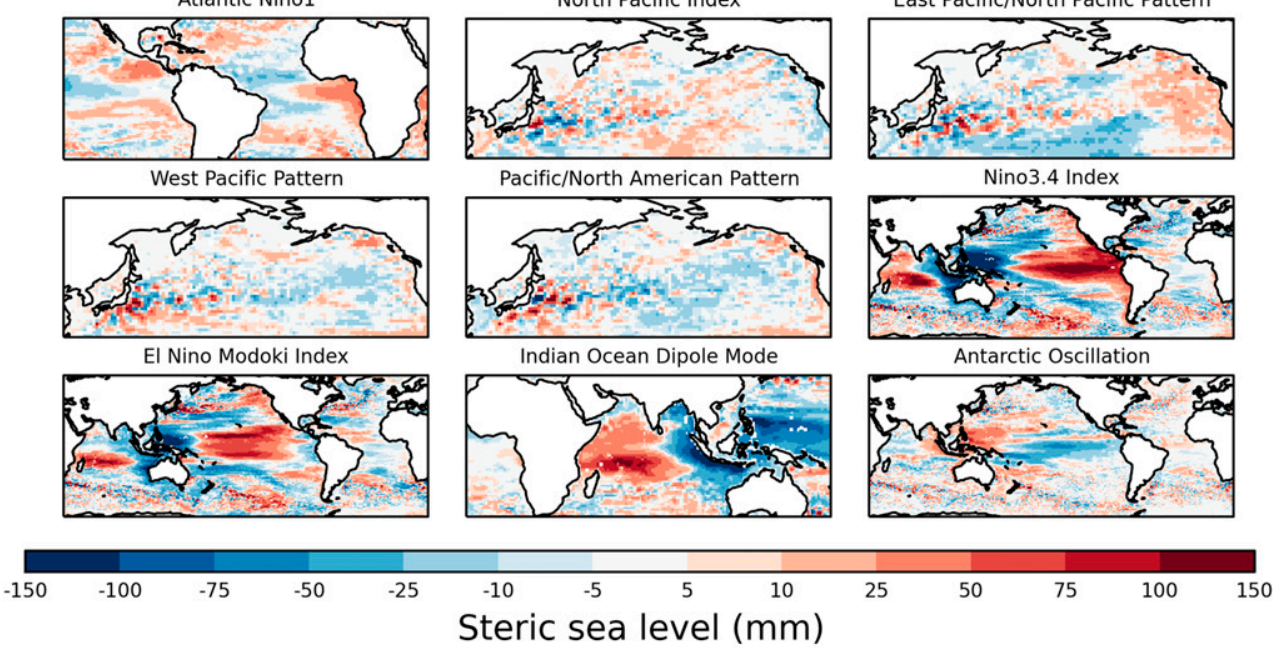

North Atlantic Oscillation

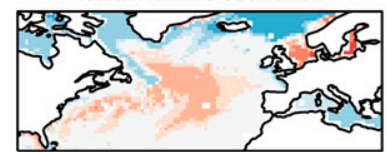

East Atlantic/Western Russia Pattern
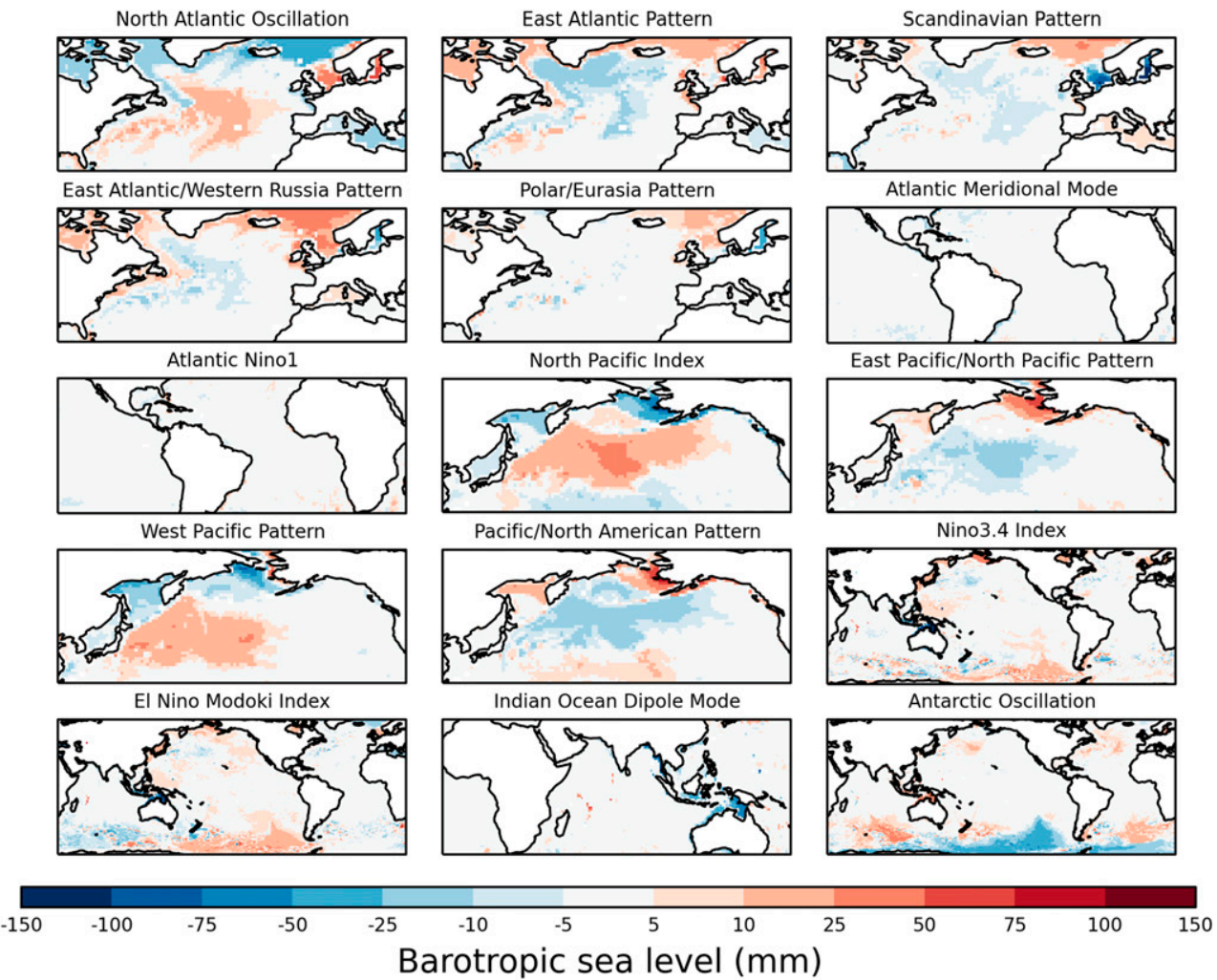

FIG. 3. As in Fig. 1, but for (top) steric and (bottom) barotropic sea level (mm) in experiment CTRL. 

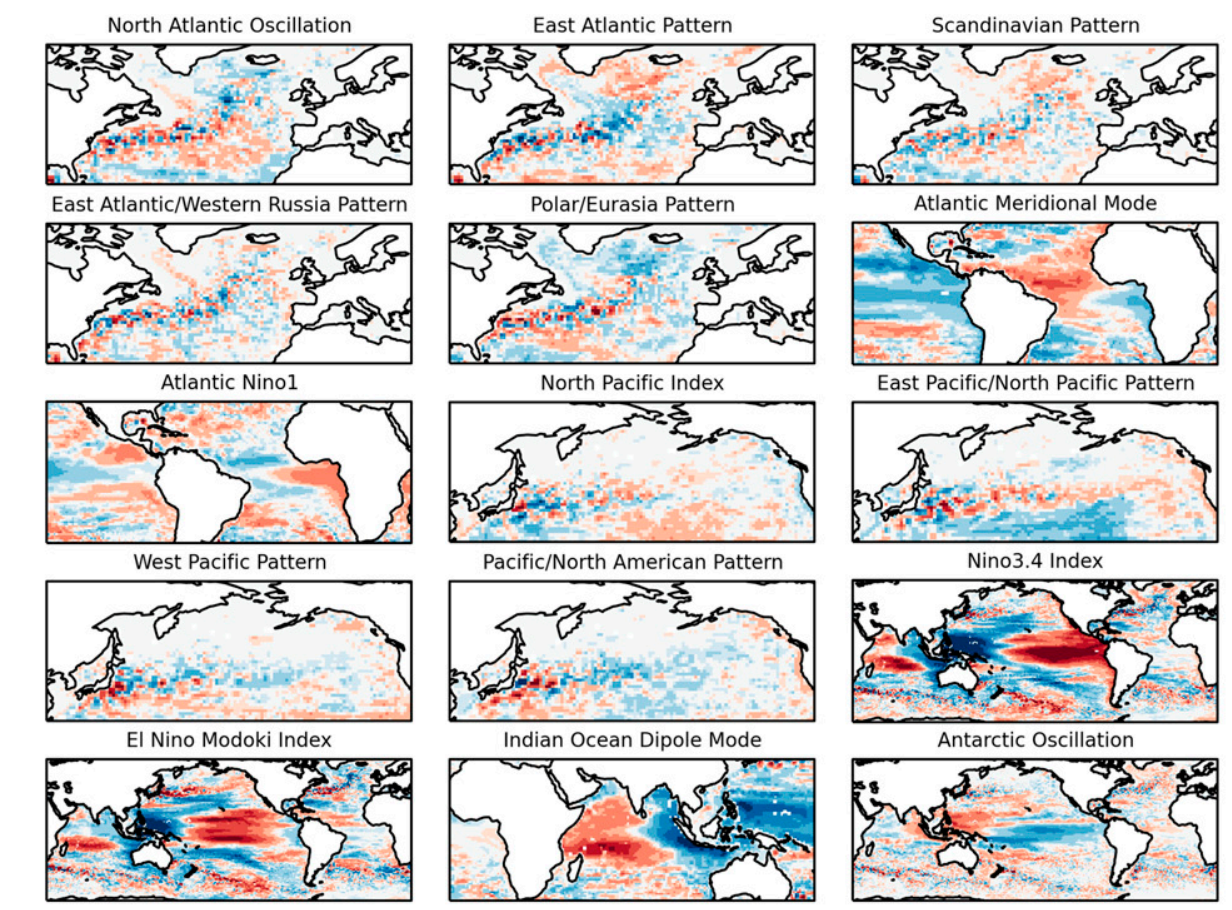

Pacific/North American Pattern
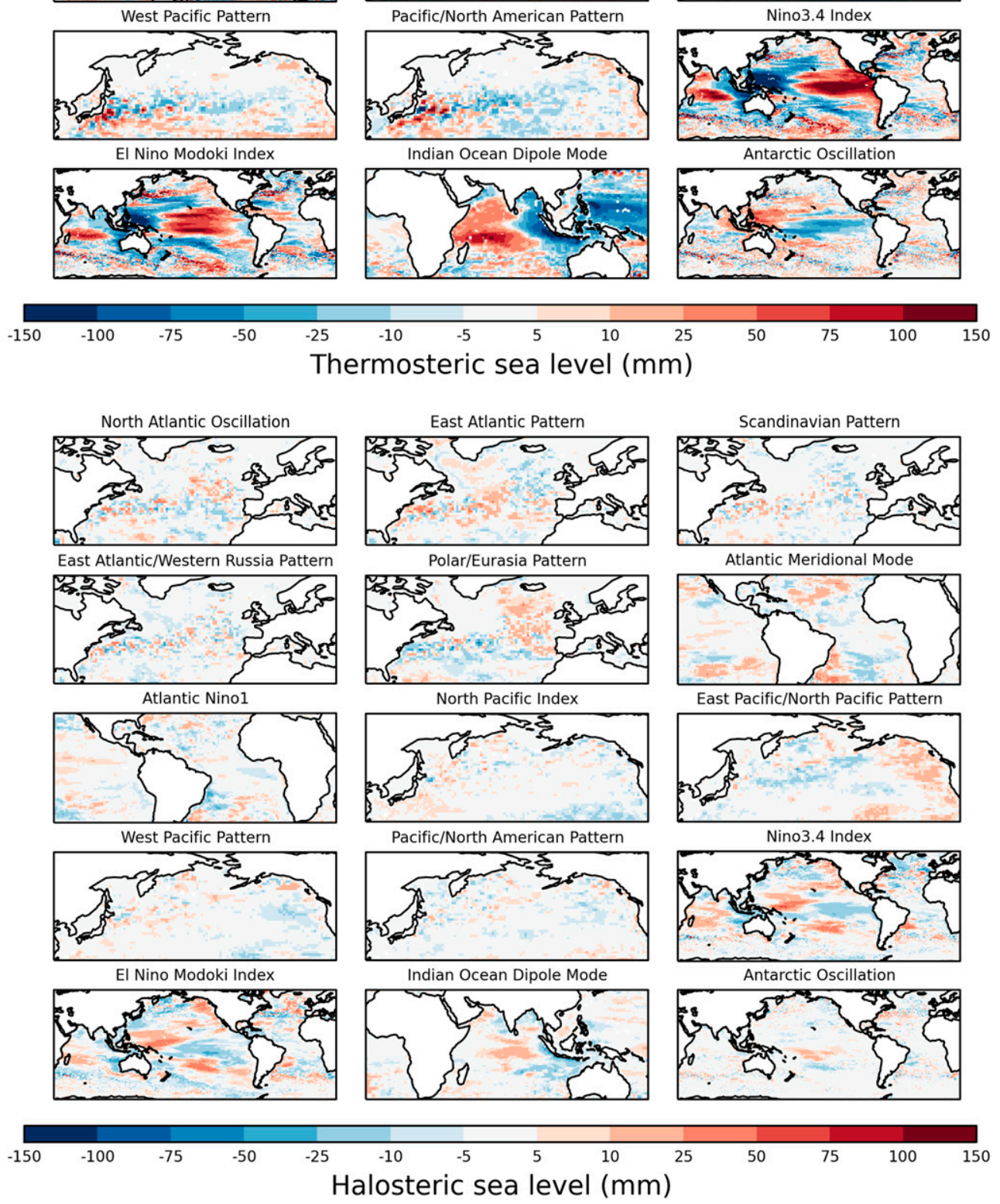

FIG. 4. As in Fig. 1, but for (top) thermosteric and (bottom) halosteric sea level (mm) in experiment CTRL. 

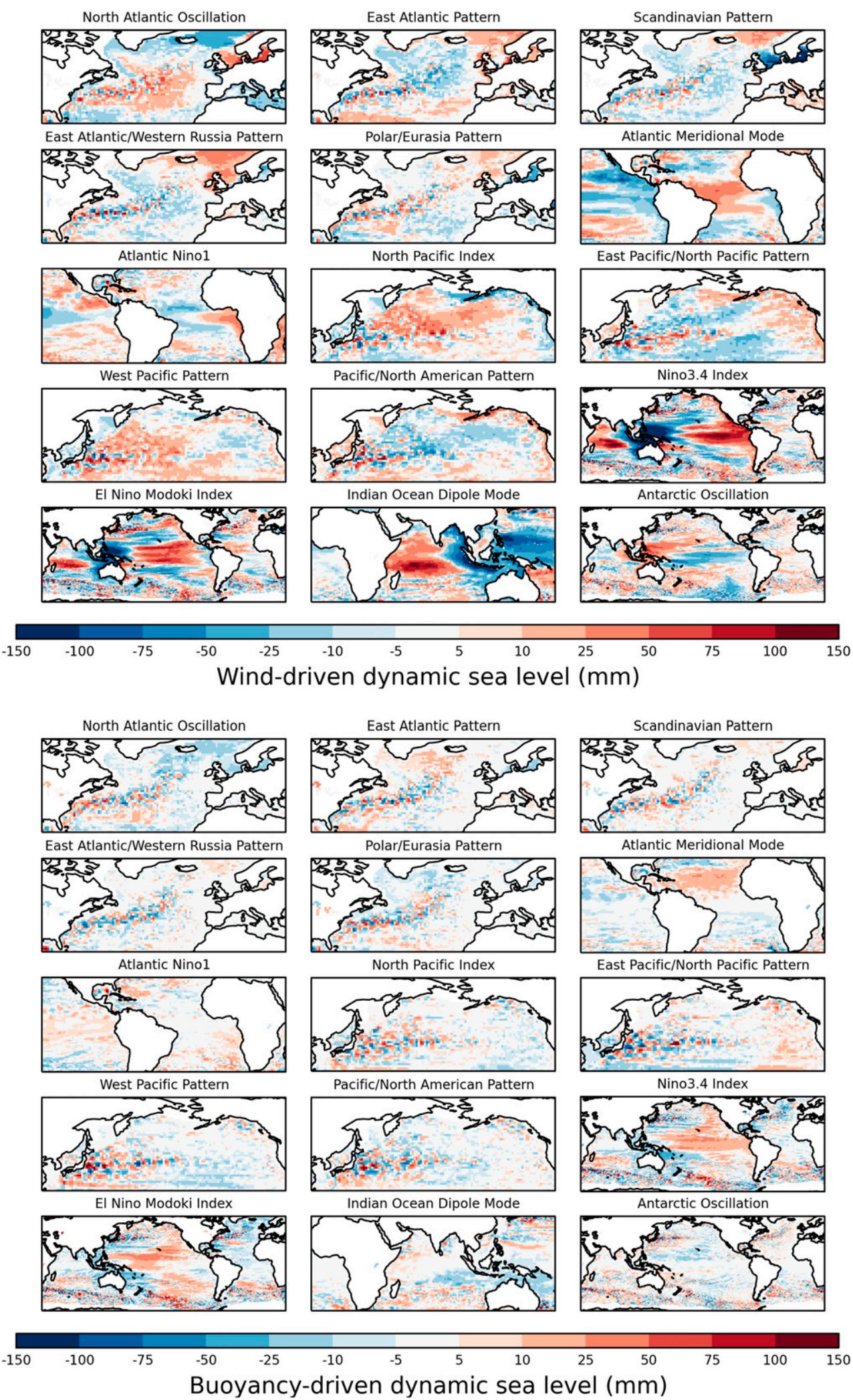

FIG. 5. As in Fig. 1, but for experiments (top) WIND and (bottom) BUOY. Regions with climatological sea ice cover exceeding $10 \%$ are masked in white as the forcing decomposition was not made for air-ice or ice-ocean fluxes. See the methods in the supplementary material for further description of the flux decomposition in our ocean model sensitivity experiments. 
with previous work that has emphasized the dominance of the winds for interannual variability of steric sea level in the North Atlantic (Esselborn and Eden 2001).

Wind forcing tends to dominate barotropic sea level variability, and previous studies have emphasized the importance of the winds in driving baroclinic waves in the tropics (e.g., Vivier et al. 1999; Wyrtki 1975). However, the specific role for the winds in driving steric variability associated with extratropical modes of variability such as the NAO and EA is less obvious. One obvious candidate is the contemporaneous steric response to local Ekman pumping that occurs in phase with changes to wind stress curl. To evaluate the importance of this process, we produce composite patterns of Ekman sea level forcing $\partial_{t} \eta_{\mathrm{Ek}}$ following Gill and Niller (1973) and Cabanes et al. (2006):

$$
\partial_{t} \eta_{\mathrm{Ek}}=\left(\frac{\rho_{\text {surface }}-\langle\rho\rangle}{\rho_{0}}\right) \times \operatorname{curl}\left(\frac{\tau}{f}\right),
$$

where $f$ is the Coriolis parameter, $\boldsymbol{\tau}$ is the wind stress vector estimated from $10-\mathrm{m}$ wind velocities, $\rho_{\text {surface }}$ is potential density at the ocean surface, and $\langle\rho\rangle$ is potential density averaged over the depth of the ocean. Note that this definition for $\partial_{t} \eta_{\mathrm{Ek}}$ is an algebraic simplification of the form presented by Cabanes et al. (2006). Our composites of $\partial_{t} \eta_{\mathrm{Ek}}$ (Fig. 2) indicate that although the steric response to Ekman pumping may contribute in some locations (e.g., in the subtropical North Atlantic during NAO events), in general the instantaneous Ekman forcing is weak compared to the magnitude of extratropical steric anomalies, even when integrated over several months. This result is consistent with previous work that found a limited role for local Ekman forcing in the North Atlantic (Cabanes et al. 2006) and indicates that other dynamic responses to wind forcing, such as changes in advection or baroclinic adjustments, must be important for steric changes associated with extratropical modes of climate variability.

To evaluate the drivers of variability on interannual time scales (defined as variations in annual means during the period 1960-2009), we calculate the fraction of variance $F$ explained by each process (Fig. 6), which is defined as

$$
F=1-\frac{\operatorname{Var}\left(\eta_{\text {signal }}-\eta_{\text {process }}\right)}{\operatorname{Var}\left(\eta_{\text {signal }}\right)},
$$

where $\eta_{\text {signal }}$ is the time-varying sea level signal and $\eta_{\text {process }}$ is the variability attributable to a specific process. A perfect score $(F=1)$ occurs when $\eta_{\text {signal }}$ and $\eta_{\text {process }}$ are perfectly correlated and have the same variance.
Consistent with previous studies (Fukumori et al. 1998; Vinogradova et al. 2007), we find that DSL variability on interannual time scales is largely steric in nature, although barotropic variations are important in the high latitudes and over shallow marginal seas (Figs. 6a,b). The reduced importance of steric variability over shallow water is a simple consequence of the limited depth over which density anomalies can be integrated. However, offshore steric variability can also play an indirect role in coastal sea level variability by inducing barotropic signals on the continental shelf associated with adjustments to density changes over sloping topography (Bingham and Hughes 2012). Locations with low values of $F$ for both steric and barotropic signals are indicative of compensation between the two processes. Separation of steric variations into thermosteric and halosteric contributions reveals that changes in temperature dominate over most of the oceans, except in the high latitudes (particularly in the Arctic and northernmost Pacific Ocean) and on the continental shelf where changes in salinity are important (Figs. 6c,d). In some regions (e.g., the subtropics in the Atlantic and South Pacific), neither thermosteric or halosteric changes alone are a good measure of the total steric signal. This indicates an important role for density compensation in these regions, a process that occurs as a result of the advection of spiciness anomalies along isopycnals (Köhl 2014).

Using the ocean model sensitivity experiments described in section 2, we also evaluate the relative importance of wind and buoyancy forcings for interannual variations in steric sea level (Figs. 6e,f). Between $20^{\circ} \mathrm{S}$ and $20^{\circ} \mathrm{N}$, almost all interannual variability of steric sea level in CTRL can be attributed to the wind forcing. This result is not surprising given the importance of winddriven baroclinic waves associated with tropical modes of climate variability (e.g., Wyrtki 1975). It is also in agreement with previous work that has linked decadal changes in tropical Pacific sea level with long-term variations in the trade winds (e.g., Merrifield et al. 2012; Merrifield and Maltrud 2011; England et al. 2014). Our experiments also show the importance of wind-driven interannual variability in the extratropics and high latitudes. This is consistent with previous works that have highlighted the role of winds on interannual time scales via their impact on baroclinic waves, quasi-steady Sverdrup balance, and Ekman pumping (e.g., Cabanes et al. 2006; Sturges et al. 1998; Piecuch and Ponte 2011). Buoyancy forcings have a limited impact on sea level in the low latitudes, but are particularly important for steric changes in the North Atlantic linked to variability of the overturning circulation (Figs. 6f,h). This result is consistent with earlier work that has linked low-frequency sea 
(a) Steric

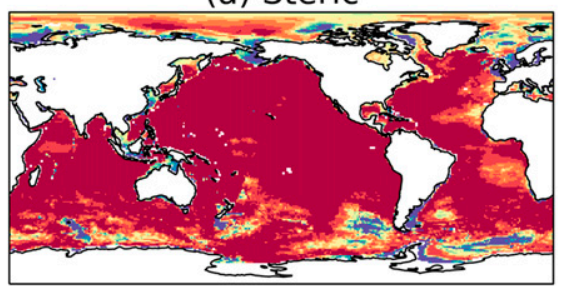

(c) Thermosteric

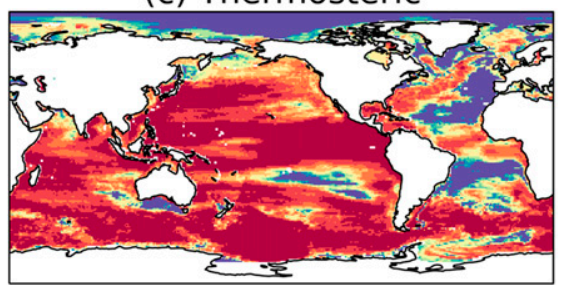

(e) WIND (steric)

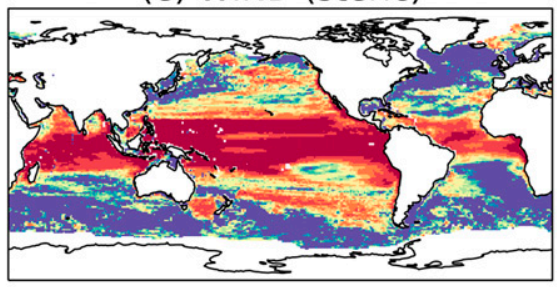

(g) WIND + BUOY (steric)

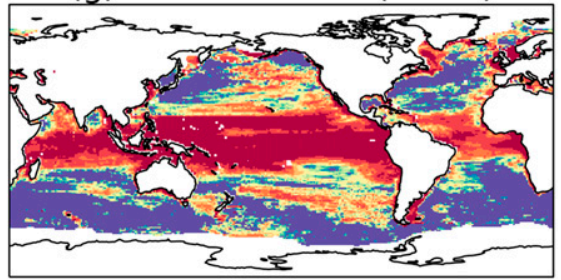

(b) Barotropic

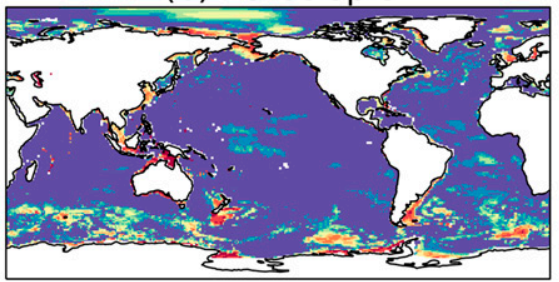

(d) Halosteric

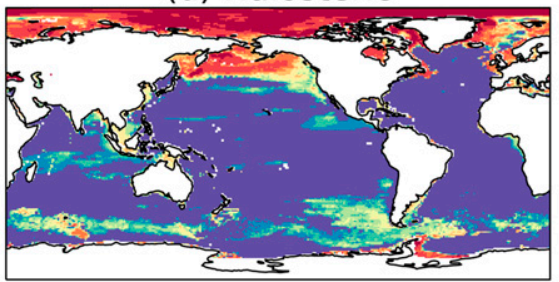

\section{(f) BUOY (steric)}

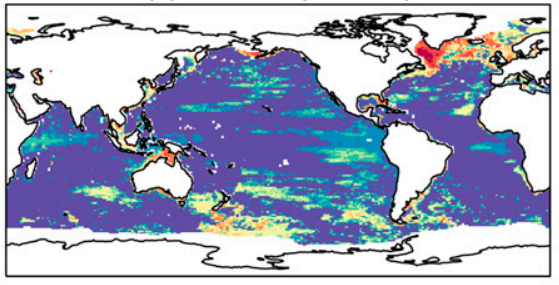

(h) Buoyancy-forced AMOC (steric)

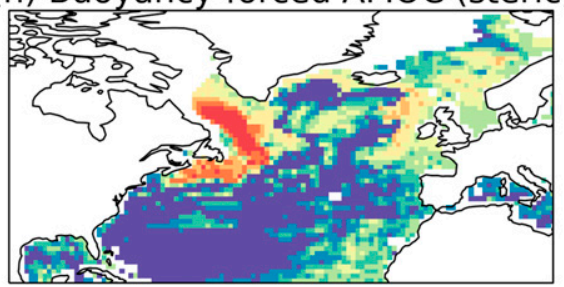

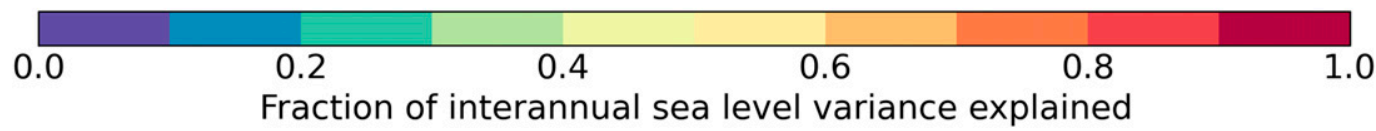

FIG. 6. Fraction of dynamic sea level variance in CTRL explained by (a) steric and (b) barotropic signals. Fraction of steric sea level variance in CTRL explained by (c) temperature and (d) salinity. Fraction of steric sea level variance in CTRL explained by (e) WIND, (f) BUOY, and (g) WIND + BUOY. (h) Coefficient of determination $r^{2}$ for the linear relationship between steric sea level and the AMOC at $26^{\circ} \mathrm{N}$ in BUOY. Skill scores are calculated using annual mean data covering the duration of the model experiments (1960-2009). In plots (e)-(h), regions with climatological sea ice cover exceeding $10 \%$ are masked in white as the forcing decomposition was not made for airice or ice-ocean fluxes.

level variability in the Gulf Stream and North Atlantic subpolar gyre with the ocean circulation response to basin-scale modes of buoyancy flux variability (Hakkinen 2001; Hakkinen and Rhines 2004).

We also linearly combine anomalies from WIND and BUOY and calculate their skill in reproducing steric anomalies in CTRL (Fig. 6g). Regions of low skill are indicative of a substantial role for intrinsic variability and/or nonlinear interactions between the response to buoyancy and wind forcings. Alternatively, regions of low skill could indicate deficiencies in our experimental design such that the combined forcings in WIND and BUOY are not exactly equal to those in CTRL (see methods in the supplementary material for further 


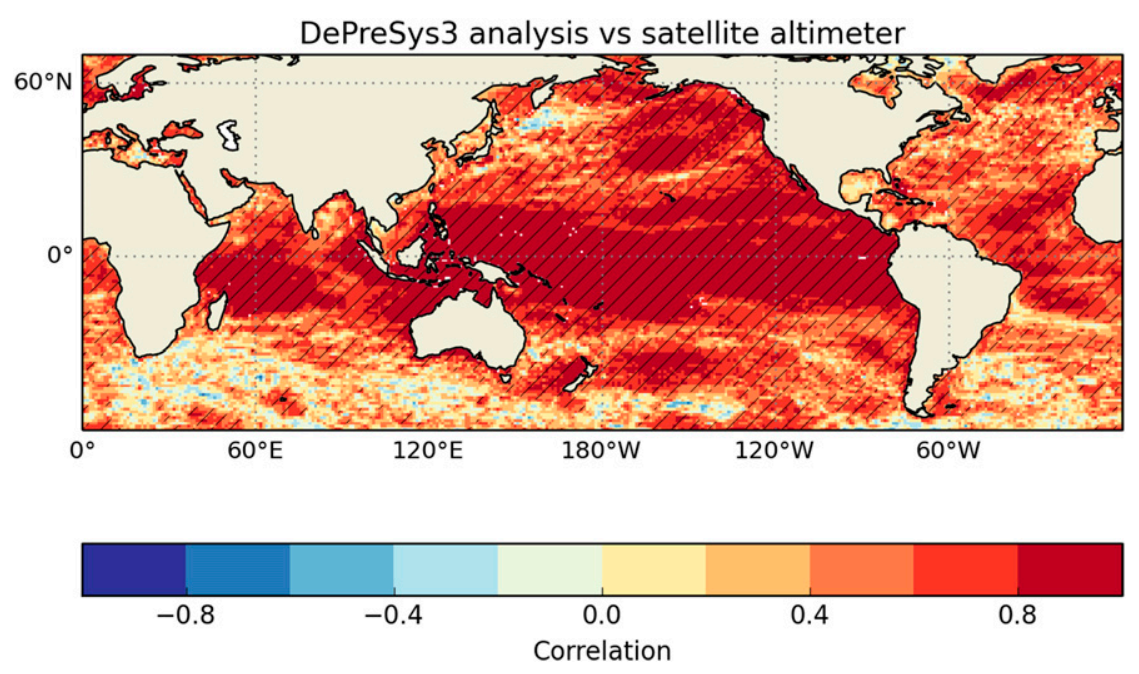

FIG. 7. Correlations for the period 1993-2013 calculated using annual mean dynamic sea level anomalies from the DePreSys3 analysis and satellite altimeter data. Hatched areas indicate regions with $|r| \geq 0.433$, the critical value corresponding to $p=0.05$ for a two-sided test assuming $N-2$ degrees of freedom, where $N=21$ is the number of years of data.

details). The regions with the lowest skill ( $<20 \%$ variance explained) are located in eddy-active regions such as the Southern Ocean and western boundary current extensions, consistent with the locations of substantial intrinsic variability identified by Penduff et al. (2011). The significant role for intrinsic variability in these regions explains why there are regions of low skill in WIND on interannual time scales, despite wind-forcing being the dominant contributor to sea level anomalies associated with modes of climate variability in the same location.

\section{Predictability of dynamic sea level}

In this section, we evaluate the predictability of DSL variability on seasonal-to-interannual time scales in a state-of-the-art coupled forecast system. Correlations of annual mean DSL anomalies from the DePreSys3 analysis and satellite altimeter data demonstrate that large-scale DSL variability is generally well captured in the state estimate we use to initialize our hindcasts (Fig. 7). As we noted earlier, no direct observations of sea level are used to constrain this analysis, so the good agreement must originate from the assimilation of temperature, salinity, and wind data. Correlations are particularly high in the tropical Pacific and Indian oceans, but generally lower in shallow enclosed seas and regions of substantial intrinsic variability. Although DePreSys3 incorporates an eddy-permitting OGCM, mesoscale variability is unable to fully develop in the observationally constrained analysis. This is because the analysis is strongly determined by the 10 -day relaxation time scale used to restore DePreSys 3 to a reconstruction of large-scale temperature and salinity anomalies (Smith and Murphy 2007; Smith et al. 2015). The restoring used in the DePreSys3 analysis does not preclude the development of eddies in individual hindcasts, but it means the mesoscale eddy field is not initialized in hindcasts or predicted as part of the ensemble mean. For this reason, we are implicitly evaluating only the ability of DePreSys3 to predict large-scale patterns of sea level variability.

To assess the skill of forecasts, correlation coefficients from DePreSys3 are compared to those calculated using a simple model of persistence. For each location, a persistence forecast is specified as the mean anomaly in the season or year preceding the initialization date. For example, persistence forecast estimates for NovemberJanuary are based on the mean anomaly for AugustOctober. For the first season following initialization (i.e., months 1-3), DePreSys3 exhibits high skill for DSL and outperforms persistence over most of the oceans (Fig. 8). Skill in DePreSys3 also exceeds persistence over most of the Pacific and large regions of the Atlantic and Indian Oceans when anomalies are averaged over the first year. Predictions are particularly good in the equatorial and tropical Pacific, which we attribute to skillful predictions of ENSO in DePreSys3 (Dunstone et al. 2016).

At lead times of 3-12 months, there is a strong reduction in the skill of persistence forecasts in the tropical Pacific and Indian Oceans. In contrast, forecasts from DePreSys 3 show a less dramatic decline in skill and continue to show significant skill in parts of the tropical Pacific for the second winter since initialization (i.e., 

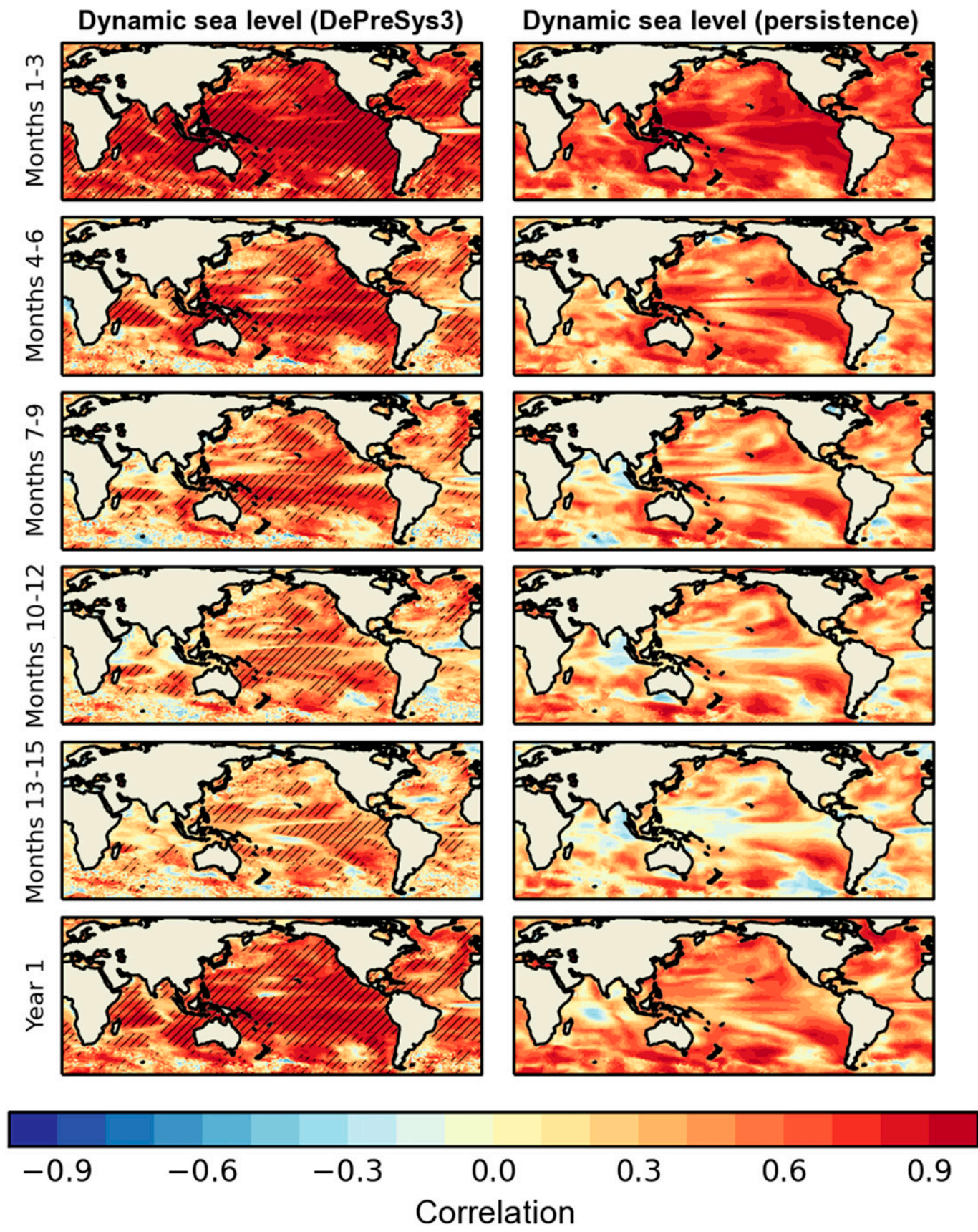

FIG. 8. Correlations for the period 1960-2013 between the DePreSys 3 hindcast ensemble mean and (left) the data assimilating DePreSys3 analysis compared with (right) persistence forecasts: (top)-(bottom) months 1-3, 4-6, 7-9, 10-12, and 13-15, and year 1. Hatching in the left panels indicates areas where correlations from DePreSys3 are greater than those for persistence and $|r| \geq 0.396$, the critical value corresponding to $p=0.05$ for a two-sided test assuming $N-2$ degrees of freedom, where $N=25$ is the number of start dates.

months 13-15). The success of DePreSys3 is a consequence of its ability to more realistically propagate thermocline depth anomalies associated with baroclinic Rossby and Kelvin waves. This is evident from the skill in predictions of the $18^{\circ} \mathrm{C}$ isotherm depth (Fig. 9). At extratropical latitudes, although DePreSys3 generally outperforms persistence when anomalies are averaged over the first year, the difference is less distinct. This is likely due to the decreasing speed of baroclinic Rossby waves with latitude that makes it harder to distinguish 

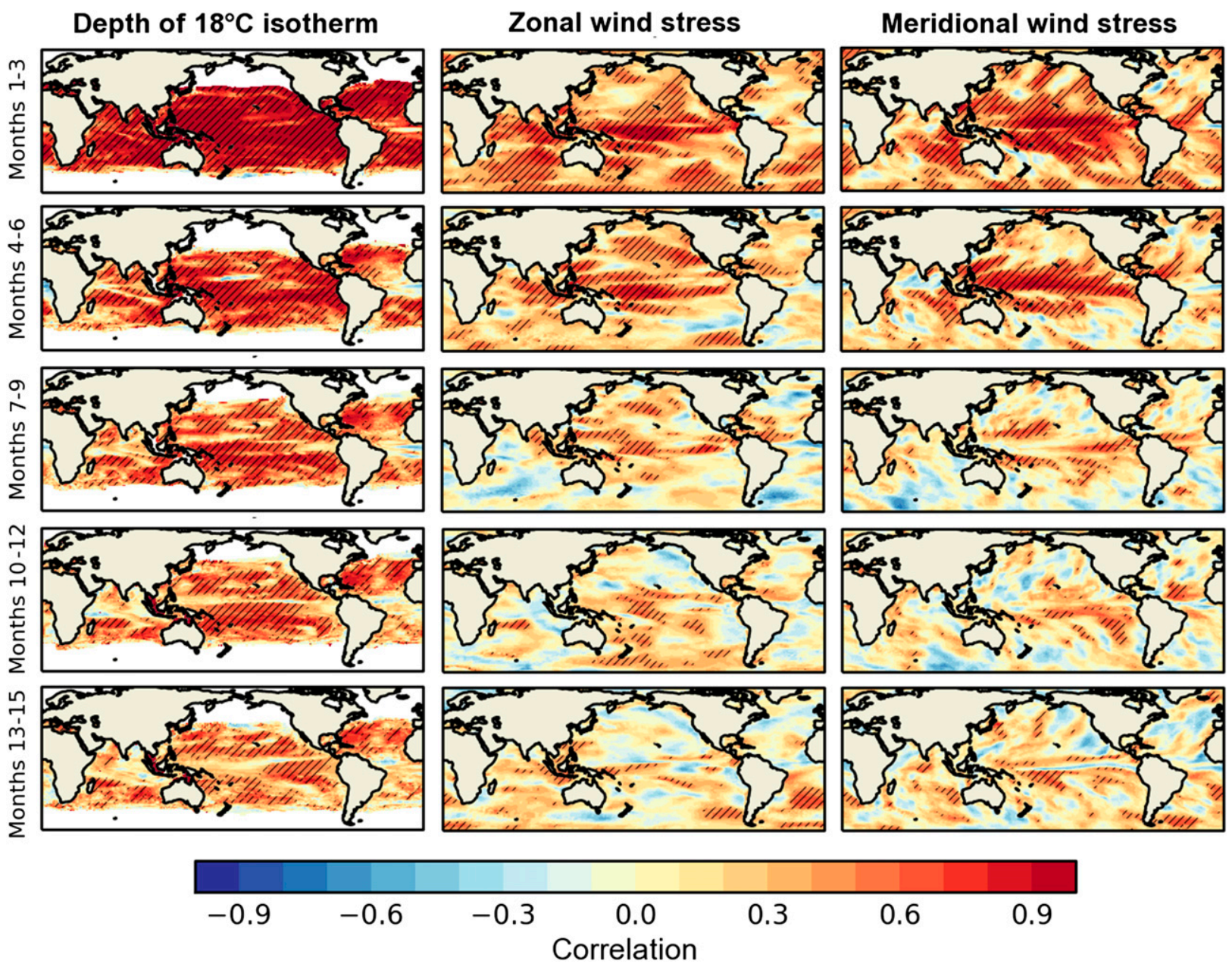

FIG. 9. Correlations for the period 1960-2013 between the DePreSys3 hindcast ensemble mean and the data assimilating DePreSys3 analysis calculated for (left) the depth of the $18^{\circ} \mathrm{C}$ isotherm and surface (center) zonal and (right) meridional wind stress for: (top)(bottom) months 1-3, 4-6, 7-9, 10-12, and 13-15. Hatching indicates areas where correlations from DePreSys3 are greater than those for persistence and $|r| \geq 0.396$, the critical value corresponding to $p=0.05$ for a two-sided test assuming $N-2$ degrees of freedom, where $N=$ 25 is the number of start dates.

between slowly propagating features and stationary anomalies (Polkova et al. 2015).

In the previous section, we emphasized the dominant role of the winds for DSL change on seasonal-tointerannual time scales, particularly for DSL anomalies associated with leading modes of climate variability. Given this knowledge, it is interesting to consider two distinct ways it is possible to predict wind-driven variability using a coupled climate model. First, accurate predictions of wind-driven signals can occur via prediction of the atmospheric state and the associated ocean response. On seasonal-to-interannual time scales, this scenario is most relevant when ocean-atmosphere variability is tightly coupled such that surface winds respond to the ocean state and vice versa. Alternatively, predictive skill can emerge by accurately initializing the ocean to contain the imprint of a previous wind-forcing (e.g., a depth anomaly in the thermocline) that is then propagated by the ocean model dynamics in the absence of skill in the atmosphere (also see Köhl 2014). In this scenario, only the slowly evolving baroclinic contributions to sea level variability will be predictable as the local (e.g., Ekman pumping) and rapid (i.e., barotropic) responses to the simulated wind field will be erroneous.

DePreSys3 has some skill in the predictability of zonal and meridional wind stress at lead times of several months, particularly in the tropical Pacific where air-sea interactions and predictability are strongly coupled (Fig. 9). However, at lead times of 6 months or more, skill in wind stress is much lower than skill for either DSL or $18^{\circ} \mathrm{C}$ isotherm depth anomalies. Based on these comparisons, it is evident that much of the DSL skill 
demonstrated by DePreSys3 must originate from the initialization and propagation of DSL anomalies by the ocean dynamics rather than the prediction of the atmospheric drivers. In the tropics, this translates to accurate predictions of DSL many months in advance, with predictability ultimately limited by the basin transit times for baroclinic adjustments. In the extratropics, although baroclinic wave speeds are much slower, the fraction of variability that can be attributed to remotely forced adjustments is also smaller. This is because local forcing from winds (e.g., Cabanes et al. 2006; Vivier et al. 1999) and rapid barotropic adjustments in response to atmospheric modes of variability (e.g., Fig. 3) are also important. Furthermore, the IB effect is nonnegligible in the extratropics. Based on this evidence, we emphasize that prediction of seasonal-to-interannual sea level variability in the extratropics will be governed to a large extent by the predictability of surface wind stress and modes of atmospheric variability.

\section{Summary and conclusions}

We have presented an analysis of satellite observations and eddy-permitting model simulations and evaluated the drivers of sea level variability associated with 15 leading modes of climate variability covering the Atlantic, Pacific, Indian, and Southern Oceans. Based on our model experiments, and consistent with previous research (e.g., Köhl 2014; Forget and Ponte 2015; Stammer et al. 2013), we find that seasonal-tointerannual sea level variations in the low latitudes are dominated by the thermosteric response to wind-driven baroclinic waves associated with tropical modes of climate variability. In the extratropics, changes to dynamic sea level associated with atmospheric modes of variability include a substantial barotropic response to wind forcing, particularly over the continental shelf seas. However, wind-driven steric changes are also important for some modes (e.g., NAO, EPNP, and EA; see Table 3). Changes in steric sea level associated with heat and freshwater forcings are generally less important, except on interannual time scales in the northwest Atlantic. In this region, low-frequency sea level variations are associated with buoyancy-forced changes in the Atlantic meridional overturning circulation (AMOC).

Using a state-of-the-art coupled forecast system (DePreSys3), we find skill in seasonal-to-interannual predictions of dynamic sea level that exceeds persistence over large regions of the Pacific, Atlantic, and Indian Oceans. Skill is particularly high in the tropical IndoPacific because of the accurate initialization and propagation of thermocline depth anomalies associated with baroclinic waves. Although we also find some skill in the extratropics that previous authors have linked to slowmoving baroclinic Rossby waves (Polkova et al. 2015), we also emphasize the role of nonsteric signals associated with modes of atmospheric variability. These additional contributions to sea level variability (including rapid barotropic adjustments, local responses to wind forcing, and the IB effect) limit the skill of extratropical sea level forecasts as they require predictability of the atmospheric state, including surface wind and pressure anomalies.

Finally, our ocean model sensitivity experiments also show the important role for intrinsic ocean variability, particularly in boundary currents and the Southern Ocean. The degree of interannual sea level predictability in these regions will thus depend on the time scales on which intrinsic variability becomes chaotic and the accuracy with which the ocean mesoscale can be initialized.

Acknowledgments. This work was supported by the Joint DECC/Defra Met Office Hadley Centre Climate Programme (GA01101) and the EU FP7 SPECS project. We thank three anonymous reviewers for useful comments that helped us to improve an earlier version of this manuscript.

\section{REFERENCES}

Ablain, M., and Coauthors, 2015: Improved sea level record over the satellite altimetry era (1993-2010) from the Climate Change Initiative Project. Ocean Sci., 11, 67-82, doi:10.5194/ os-11-67-2015.

Antonov, J. I., S. Levitus, and T. P. Boyer, 2002: Steric sea level variations during 1957-1994: Importance of salinity. J. Geophys. Res., 107, 8013, doi:10.1029/2001JC000964.

Ashok, K., S. K. Behera, S. A. Rao, H. Weng, and T. Yamagata, 2007: El Niño Modoki and its possible teleconnection. J. Geophys. Res., 112, C11, doi:10.1029/2006JC003798.

Barnston, A. G., and R. E. Livezey, 1987: Classification, seasonality and persistence of low-frequency atmospheric circulation patterns. Mon. Wea. Rev., 115, 1083-1126, doi:10.1175/ 1520-0493(1987)115<1083:CSAPOL>2.0.CO;2.

Becker, M., B. Meyssignac, C. Letetrel, W. Llovel, A. Cazenave, and T. Delcroix, 2012: Sea level variations at tropical Pacific islands since 1950. Global Planet. Change, 80-81, 85-98, doi:10.1016/j.gloplacha.2011.09.004.

Bingham, R. J., and C. W. Hughes, 2012: Local diagnostics to estimate density-induced sea level variations over topography and along coastlines. J. Geophys. Res., 117, C01013, doi:10.1029/2011JC007276.

Cabanes, C., T. Huck, and A. Colin de Verdière, 2006: Contributions of wind forcing and surface heating to interannual sea level variations in the Atlantic Ocean. J. Phys. Oceanogr., 36, 1739-1750, doi:10.1175/JPO2935.1.

Cazenave, A., and W. Llovel, 2010: Contemporary sea level rise. Annu. Rev. Mar. Sci., 2, 145-173, doi:10.1146/annurev-marine-120308-081105.

Chelton, D. B., and R. E. Davis, 1982: Monthly mean sea-level variability along the west coast of North America. J. Phys. 
Oceanogr., 12, 757-784, doi:10.1175/1520-0485(1982)012<0757: MMSLVA $>2.0 . \mathrm{CO} ; 2$.

_- M. G. Schlax, R. M. Samelson, and R. A. de Szoeke, 2007: Global observations of large oceanic eddies. Geophys. Res. Lett., 34, L15606, doi:10.1029/2007GL030812.

Chiang, J. C. H., and D. J. Vimont, 2004: Analogous meridional modes of atmosphere-ocean variability in the tropical Pacific and tropical Atlantic. J. Climate, 17, 4143-4158, doi:10.1175/ JCLI4953.1.

Chowdhury, M. R., P.-S. Chu, T. Schroeder, and N. Colasacco, 2007: Seasonal sea-level forecasts by canonical correlation analysis-An operational scheme for the US-affiliated Pacific Islands. Int. J. Climatol., 27, 1389-1402, doi:10.1002/joc.1474.

,-- , and C. C. Guard, 2014: An improved sea level forecasting scheme for hazards management in the US-affiliated Pacific Islands. Int. J. Climatol., 34, 2320-2329, doi:10.1002/ joc.3841.

Church, J. A., and N. J. White, 2011: Sea-level rise from the late 19 th to the early 21 st century. Surv. Geophys., 32, 585-602, doi:10.1007/s10712-011-9119-1.

Cummins, P. F., and G. S. E. Lagerloef, 2004: Wind-driven interannual variability over the northeast Pacific Ocean. Deep Sea Res. I, 51, 2105-2121, doi:10.1016/j.dsr.2004.08.004.

Dee, D. P., and Coauthors, 2011: The ERA-Interim reanalysis: Configuration and performance of the data assimilation system. Quart. J. Roy. Meteor. Soc., 137, 553-507, doi:10.1002/ qj.828.

Dunstone, N., D. Smith, A. Scaife, L. Hermanson, R. Ease, N. Robinson, M. Andrews, and J. Knight, 2016: Skillful predictions of the winter North Atlantic oscillation one year ahead. Nature Geosci., in press.

Enfield, D. B., and J. S. Allen, 1980: On the structure and dynamics of monthly mean sea level anomalies along the Pacific coast of North and South America. J. Phys. Oceanogr., 10, 557-578, doi:10.1175/1520-0485(1980)010<0557:OTSADO > 2.0.CO;2.

England, M. H., and Coauthors, 2014: Recent intensification of wind-driven circulation in the Pacific and the ongoing warming hiatus. Nat. Climate Change, 4, 222-227, doi:10.1038/ nclimate2106.

Esselborn, S., and C. Eden, 2001: Sea surface height changes in the North Atlantic Ocean related to the North Atlantic Oscillation. Geophys. Res. Lett., 28, 3473-3476, doi:10.1029/ 2001 GL012863.

Fagherazzi, S., G. Fosser, L. D'Alpaos, and P. D'Odorico, 2005: Climatic oscillations influence the flooding of Venice. Geophys. Res. Lett., 32, L19710, doi:10.1029/2005GL023758.

Ferry, N., G. Reverdin, and A. Oschlies, 2000: Seasonal sea surface height variability in the North Atlantic Ocean. J. Geophys. Res., 105, 6307-6326, doi:10.1029/1999JC900296.

Forget, G., and R. M. Ponte, 2015: The partition of regional sea level variability. Prog. Oceanogr., 137, 173-195, doi:10.1016/ j.pocean.2015.06.002.

Frankignoul, C., P. Müller, and E. Zorita, 1997: A simple model of the decadal response of the ocean to stochastic wind forcing. J. Phys. Oceanogr., 27, 1533-1546, doi:10.1175/1520-0485(1997)027<1533: ASMOTD $>2.0 . C O ; 2$.

Fukumori, I., R. Raghunath, and L.-L. Fu, 1998: Nature of global large-scale sea level variability in relation to atmospheric forcing: A modeling study. J. Geophys. Res., 103, 5493-5512, doi:10.1029/97JC02907.

Gill, A. E., and P. P. Niller, 1973: The theory of the seasonal variability in the ocean. Deep-Sea Res. Oceanogr. Abstr., 20,141177, doi:10.1016/0011-7471(73)90049-1.
Goddard, P. B., J. Yin, S. M. Griffies, and S. Zhang, 2015: An extreme event of sea-level rise along the Northeast coast of North America in 2009-2010. Nat. Commun., 6, 6346, doi:10.1038/ncomms7346.

Häkkinen, S., 2001: Variability in sea surface height: A qualitative measure for the meridional overturning in the North Atlantic. J. Geophys. Res., 106, 13 837-13 848, doi:10.1029/ 1999JC000155.

— , and P. B. Rhines, 2004: Decline of subpolar North Atlantic circulation during the 1990s. Science, 304, 555-559, doi:10.1126/science.1094917.

Hunke, E. C., and W. H. Lipscomb, 2010: CICE: The Los Alamos Sea Ice Model documentation and software user's manual, version 4.1. Doc. LA-CC-06-012, 76 pp. [Available online at http://csdms.colorado.edu/w/images/CICE_documentation_and_ software_user's_manual.pdf.]

Jacobs, G. A., H. E. Hurlburt, J. C. Kindle, E. J. Metzger, J. L. Mitchell, W. J. Teague, and A. J. Wallcraft, 1994: Decadescale trans-Pacific propagation and warming effects of an El-Nino anomaly. Nature, 370, 360-363, doi:10.1038/ 370360a0

Kalnay, E., and Coauthors, 1996: The NCEP/NCAR 40-Year Reanalysis Project. Bull. Amer. Meteor. Soc., 77, 437-471, doi:10.1175/1520-0477(1996)077<0437:TNYRP>2.0.CO;2.

Kelly, K. A., M. J. Caruso, and J. A. Austin, 1993: Wind-forced variations in sea surface height in the northeast Pacific Ocean. J. Phys. Oceanogr., 23, 2392-2411, doi:10.1175/1520-0485(1993)023<2392: WFVISS $>2.0 . \mathrm{CO} ; 2$.

Knight, J. F., and Coauthors, 2014: Predictions of climate several years ahead using an improved decadal prediction system. J. Climate, 27, 7550-7567, doi:10.1175/JCLI-D-14-00069.1.

Köhl, A., 2014: Detecting processes contributing to interannual halosteric and thermosteric sea level variability. J. Climate, 27, 2417-2426, doi:10.1175/JCLI-D-13-00412.1.

Large, W. G., and S. G. Yeager, 2004: Diurnal to decadal global forcing for ocean and sea-ice models: The data sets and flux climatologies. NCAR Tech. Note NCAR/TN-460+STR, 105 pp., doi:10.5065/D6KK98Q6.

— , and —, 2009: The global climatology of an interannually varying air-sea flux data set. Climate Dyn., 33, 341-364, doi:10.1007/s00382-008-0441-3.

Lutz, K., J. Rathmann, and J. Jacobeit, 2013: Classification of warm and cold water events in the eastern tropical Atlantic Ocean. Atmos. Sci. Lett., 14, 102-106, doi:10.1002/asl2.424.

MacLachlan, C., and Coauthors, 2015: Global Seasonal forecast system version 5 (GloSea5): A high-resolution seasonal forecast system. Quart. J. Roy. Meteor. Soc., 141, 1072-1084, doi:10.1002/qj.2396.

Madec, G., 2008: NEMO ocean engine, version 3.0. IPSL Pole Modelization Note 27, 209 pp. [Available online at http:// www.nemo-ocean.eu/content/download/5302/31828/file/ NEMO_book.pdf.]

McGregor, S., N. J. Holbrook, and S. B. Power, 2007: Interdecadal sea surface temperature variability in the equatorial Pacific Ocean. Part I: The role of off-equatorial wind stresses and oceanic Rossby waves. J. Climate, 20, 2643-2658, doi:10.1175/ JCLI4145.1.

McIntosh, P. C., J. A. Church, E. R. Miles, K. Ridgway, and C. M. Spillman, 2015: Seasonal coastal sea level prediction using a dynamical model. Geophys. Res. Lett., 42, 6747-6753, doi:10.1002/2015GL065091.

Megann, A., and Coauthors, 2014: GO5.0: The joint NERC-Met Office NEMO global ocean model for use in coupled and 
forced applications. Geosci. Model Dev., 7, 1069-1092, doi:10.5194/gmd-7-1069-2014.

Meinshausen, M., and Coauthors, 2011: The RCP greenhouse gas concentrations and their extensions from 1765 to 2300 . Climatic Change, 109, 213-241, doi:10.1007/s10584-011-0156-z.

Menéndez, M., and P. L. Woodworth, 2010: Changes in extreme high water levels based on a quasi-global tide-gauge data set. J. Geophys. Res., 115, C10011, doi:10.1029/2009JC005997.

Merrifield, M. A., and M. E. Maltrud, 2011: Regional sea level trends due to a Pacific trade wind intensification. Geophys. Res. Lett., 38, L21605, doi:10.1029/2011GL049576.

_ , P. R. Thompson, and M. Lander, 2012: Multidecadal sea level anomalies and trends in the western tropical Pacific. Geophys. Res. Lett., 39, L13602, doi:10.1029/2012GL052032.

Miles, E. R., C. M. Spillman, J. A. Church, and P. C. McIntosh, 2014: Seasonal prediction of global sea level anomalies using an ocean-atmosphere dynamical model. Climate Dyn., 43, 2131-2145, doi:10.1007/s00382-013-2039-7.

Mo, K. C., 2000: Relationships between low-frequency variability in the Southern Hemisphere and sea surface temperature anomalies. J. Climate, 13, 3599-3610, doi:10.1175/1520-0442(2000)013<3599: RBLFVI $>2.0 . \mathrm{CO} ; 2$.

Nicholls, R. J., and A. Cazenave, 2010: Sea-level rise and its impact on coastal zones. Science, 328, 1517-1520, doi:10.1126/ science. 1185782.

— , F. M. J. Hoozemans, and M. Marchand, 1999: Increasing flood risk and wetland losses due to global sea-level rise: Regional and global analyses. Global Environ. Change, 9, S69S87, doi:10.1016/S0959-3780(99)00019-9.

Penduff, T., M. Juza, L. Brodeau, G. C. Smith, B. Barnier, J.-M. Molines, A.-M. Treguier, and G. Madec, 2010: Impact of global ocean model resolution on sea-level variability with emphasis on interannual time scales. Ocean Sci., 6, 269-284, doi:10.5194/os-6-269-2010.

, _— B. Barnier, J. Zika, W. K. Dewar, A.-M. Treguier, J.-M. Molines, and N. Audiffren, 2011: Sea level expression of intrinsic and forced ocean variabilities at interannual time scales. J. Climate, 24, 5652-5670, doi:10.1175/JCLI-D-11-00077.1.

Piecuch, C. G., and R. M. Ponte, 2011: Mechanisms of interannual steric sea level variability. Geophys. Res. Lett., 38, L15605, doi:10.1029/2011GL048440.

_ , K. J. Quinn, and R. M. Ponte, 2013: Satellite-derived interannual ocean bottom pressure variability and its relation to sea level. Geophys. Res. Lett., 40, 3106-3110, doi:10.1002/grl.50549.

Polkova, I., A. Köhl, and D. Stammer, 2014: Impact of initialization procedures on the predictive skill of a coupled oceanatmosphere model. Climate Dyn., 42, 3151-3169, doi:10.1007/ s00382-013-1969-4.

,$- \ldots$, and — 2015: Predictive skill for regional interannual steric sea level and mechanisms for predictability. J. Climate, 28, 7407-7419, doi:10.1175/JCLI-D-14-00811.1.

Qiu, B., 2002: Large-scale variability in the midlatitude subtropical and subpolar North Pacific Ocean: Observations and causes. J. Phys. Oceanogr., 32, 353-375, doi:10.1175/1520-0485(2002)032<0353: LSVITM $>2.0 . \mathrm{CO} ; 2$

—_, and S. Chen, 2006: Decadal variability in the large-scale sea surface height field of the South Pacific Ocean: Observations and causes. J. Phys. Oceanogr., 36, 1751-1762, doi:10.1175/ JPO2943.1.

- and - 2010: Interannual-to-decadal variability in the bifurcation of the North Equatorial Current off the Philippines. J. Phys. Oceanogr., 40, 2525-2538, doi:10.1175/ 2010JPO4462.1.
Rayner, N. A., D. E. Parker, E. B. Horton, C. K. Folland, L. V. Alexander, D. P. Rowell, E. C. Kent, and A. Kaplan, 2003: Global analyses of sea surface temperature, sea ice, and night marine air temperature since the late nineteenth century. J. Geophys. Res., 108, 4407, doi:10.1029/2002JD002670.

Roberts, C. D., and Coauthors, 2013: Atmosphere drives recent interannual variability of the Atlantic meridional overturning circulation at $26.5^{\circ} \mathrm{N}$. Geophys. Res. Lett., 40, 5164-5170, doi:10.1002/grl.50930.

Saji, N. H., B. N. Goswami, P. N. Vinayachandran, and T. Yamagata, 1999: A dipole mode in the tropical Indian Ocean. Nature, 401 (6751), 360-363.

Smith, D. M., and J. M. Murphy, 2007: An objective ocean temperature and salinity analysis using covariances from a global climate model. J. Geophys. Res., 112, C02022, doi:10.1029/ 2006JD007574.

— R. Eade, and H. Pohlmann, 2013: A comparison of full-field and anomaly initialization for seasonal to decadal climate prediction. Climate Dyn., 41, 3325-3338, doi:10.1007/ s00382-013-1683-2.

— , and Coauthors, 2015: Earth's energy imbalance since 1960 in observations and CMIP5 models. Geophys. Res. Lett., 42 , 1205-1213, doi:10.1002/2014GL062669.

Stammer, D., 1997: Steric and wind-induced changes in TOPEX/ POSEIDON large-scale sea surface topography observations. J. Geophys. Res., 102, 20 987-21 009, doi:10.1029/ 97JC01475.

_ - A. Cazenave, R. M. Ponte, and M. E. Tamisiea, 2013: Causes for contemporary regional sea level changes. Annu. Rev. Mar. Sci., 5, 21-46, doi:10.1146/annurev-marine-121211-172406.

Sturges, W., and B. G. Hong, 1995: Wind forcing of the Atlantic thermocline along $32^{\circ} \mathrm{N}$ at low frequencies. J. Phys. Oceanogr., 25, 1706-1715, doi:10.1175/1520-0485(1995)025<1706: WFOTAT $>2.0 . \mathrm{CO} ; 2$.

, _ _ and A. J. Clarke, 1998: Decadal wind forcing of the North Atlantic subtropical gyre. J. Phys. Oceanogr., 28, 659-668, doi:10.1175/1520-0485(1998)028<0659:DWFOTN > 2.0.CO;2.

Taylor, K. E., R. J. Stouffer, and G. A. Meehl, 2012: An overview of CMIP5 and the experiment design. Bull. Amer. Meteor. Soc., 93, 485-498, doi:10.1175/BAMS-D-11-00094.1.

Timmermann, A., S. McGregor, and F.-F. Jin, 2010: Wind effects on past and future regional sea level trends in the southern Indo-Pacific. J. Climate, 23， 4429-4437, doi:10.1175/ 2010JCLI3519.1.

Trenberth, K. E., 1997: The definition of El Niño. Bull. Amer. Meteor. Soc., 78, 2771-2777, doi:10.1175/1520-0477(1997)078<2771: TDOENO $>2.0 . \mathrm{CO} ; 2$.

— tions in the Pacific. Climate Dyn., 9, 303-319, doi:10.1007/ BF00204745.

Tsimplis, M. N., A. G. Shaw, R. A. Flather, and D. K. Woolf, 2006: The influence of the North Atlantic Oscillation on the sealevel around the northern European coasts reconsidered: The thermosteric effects. Philos. Trans. Roy. Soc. London, A364, 845-856, doi:10.1098/rsta.2006.1740.

Vinogradova, N. T., R. M. Ponte, and D. Stammer, 2007: Relation between sea level and bottom pressure and the vertical dependence of oceanic variability. Geophys. Res. Lett., 34, L03608, doi:10.1029/2006GL028588.

Vivier, F., K. A. Kelly, and L. Thompson, 1999: Contributions of wind forcing, waves, and surface heating to sea surface height observations in the Pacific Ocean. J. Geophys. Res., 104, 20 767-20 788, doi:10.1029/1999JC900096. 
Williams, K., and Coauthors, 2015: The Met Office Global Coupled model 2.0 (GC2) configuration. Geosci. Model Dev., 8, 15091524, doi:10.5194/gmd-8-1509-2015.

Wong, P. P., I. J. Losada, J.-P. Gattuso, J. Hinkel, A. Khattabi, K. L. McInnes, Y. Saito, and A. Sallenger, 2014: Coastal systems and low-lying areas. Climate Change 2014: Impacts, Adaptation, and Vulnerability. Part A: Global and Sectoral Aspects. C. B. Field et al., Eds., Cambridge University Press, 361-410.

Woodworth, P. L., R. A. Flather, J. A. Williams, S. L. Wakelin, and S. Jevrejeva, 2007: The dependence of UK extreme sea levels and storm surges on the North Atlantic Oscillation. Cont. Shelf Res., 27, 935-946, doi:10.1016/j.csr.2006.12.007.

Woolf, D. K., A. G. P. Shaw, and M. N. Tsimplis, 2003: The influence of the North Atlantic Oscillation on sea-level variability in the North Atlantic region. J. Atmos. Ocean Sci., 9, 145-167, doi:10.1080/10236730310001633803.

Wyrtki, K., 1975: El Niño-The dynamic response of the equatorial Pacific oceanto atmospheric forcing. J. Phys. Oceanogr., 5, 572584, doi:10.1175/1520-0485(1975)005<0572:ENTDRO > 2.0.CO;2.

Xue, Y., and A. Leetmaa, 2000: Forecasts of tropical Pacific SST and sea level using a Markov model. Geophys. Res. Lett., 27, 2701-2704, doi:10.1029/1999GL011107.

Yan, Z., M. N. Tsimplis, and D. Woolf, 2004: Analysis of the relationship between the North Atlantic oscillation and sea-level changes in northwest Europe. Int. J. Climatol., 24, 743-758, doi:10.1002/joc.1035.

Zhang, X., and J. A. Church, 2012: Sea level trends, interannual and decadal variability in the Pacific Ocean. Geophys. Res. Lett., 39, L21701, doi:10.1029/2012GL053240. 